\title{
Study on advanced snow information and its application to disaster mitigation: An overview
}

\author{
Sento NAKAI ${ }^{1 *}$, Kenji KOSUGI ${ }^{2}$, Satoru YAMAGUCHI ${ }^{1}$, Katsuya YAMASHITA ${ }^{1}$, Kengo SATO $^{2}$, \\ Satoru ADACHI ${ }^{2}$, Yoichi ITO', Masaki NEMOTO ${ }^{2}$, Kazuki NAKAMURA ${ }^{2}$, Hiroki MOTOYOSHI', \\ Hiroyuki HIRASHIMA ${ }^{1}$, Isao KAMIISHI ${ }^{1}$, Kenichi ODA ${ }^{3}$, Masaaki ISHIZAKA ${ }^{1}$, Osamu ABE $^{2}$ and \\ Takeshi SATO ${ }^{4}$ \\ 1 Snow and Ice Research Center, National Research Institute for Earth Science and Disaster Resilience, Suyoshi, Nagaoka, Niigata, 940-0821 Japan \\ *saint@bosai.go.jp \\ 2 Shinjo Cryospheric Environment Laboratory, Snow and Ice Research Center, National Research Institute for Earth Science and Disaster \\ Resilience, 1400 Tokamachi, Shinjo, Yamagata 996-0091 Japan \\ 3 College of Science and Technology, Nihon University, 8-14, Kanda-Surugadai 1-chome, Chiyoda, Tokyo 101-8308 Japan \\ 4 National Research Institute for Earth Science and Disaster Resilience, 3-1, Tennodai, Tsukuba, Ibaraki $305-0006$ Japan
}

(Received February 6, 2018; Revised manuscript accepted January 25, 2019)

\begin{abstract}
An overview of the National Research Institute for Earth Science and Disaster Resilience (NIED) project "Study on Advanced Snow Information and its Application to Disaster Mitigation (ASDIM)" is described here. The Concentrated Snowfall Monitoring System (CSMS) was constructed, and observations of falling snow particles at remote sites of the CSMS were started within the observation range of an X-band multiparameter radar at the Snow and Ice Research Center (SIRC) in Nagaoka. A parameter for the quantitative description of falling snow particles was derived. Preferential flow within the snowpack was reproduced numerically. State-of-the-art microphysical technologies, such as nuclear magnetic resonance imaging and X-ray computerized tomography, were employed. Advanced snow information, such as center of mass flux distribution, liquid water fraction, specific surface area, and microstructure of the snowpack, were collected for falling and ground snow analyses. A regularly updated Real-time Hazard Map (RHM) displaying the areas affected by various snow and ice-related hazards was developed. The RHM serves as a platform for application of the Snow Disaster Forecasting System to hazards such as avalanches, snow accretion, and blowing snow. The utility of the RHMs was examined through experiments conducted in association with local governments and transport administrators.
\end{abstract}

Key words: Concentrated Snowfall Monitoring System, Real-time Hazard Map, Snow and Ice Disaster Forecast, $\mathrm{CMF}, \mathrm{SSA}$

\section{Introduction}

Snow and ice disasters include a wide range of damage and accidents. Avalanches, poor visibility by blowing snow, and snowdrifts can cause accidents (Abe $e t$ al., 2012; NIED, 2016). Heavy snowfall can cause traffic jams (De Freitas, 1975; Call, 2005; Nakai and Yamaguchi, 2012; Motoyoshi and Nakai, 2012), as well as the collapse of houses and the capsizing of ships under the weight of snow (Ishizaka and Nohguchi, 2012; Sato, 2012; NIED, 2016). Snow/ice accretion and the resultant fallen trees can cause electric power failure (Wakahama et al., 1977; Wakahama, 1979; Call, 2010; Cerruti and Decker, 2012; Sanders and Barjenbruch, 2016; Kumjian and Lombardo, 2017), and, for example, the destruction of cars due to dense accreted snow/ice bodies falling from overhead architecture.
In Japan, snow and ice disasters are estimated to cause, on average, 166 deaths and 626 accidents per year (Fig. 1), although the actual values may be slightly higher, since the numbers from the winter of 2013/2014 (shown in Fig. 1) are considered to be significantly underestimated compared to those of other winters with similar seasonal snowfall depth index (SSDI) values and to other statistics of the number of mortalities. The SSDI is the average normalized snowfall, as defined by Nakai (2015). The SSDI over Japan indicates no particular trend in the snowfall amount over the past 16 years. The SSDI varies significantly on an annual basis, and the number of mortalities and accidents roughly follow this variation, but with a slightly decreasing trend. Assuming this is true, the various countermeasures employed have effectively improved the resilience to snow and icerelated disasters, although the annual mortality rate ascribed to them continues to exceed 100 . The 


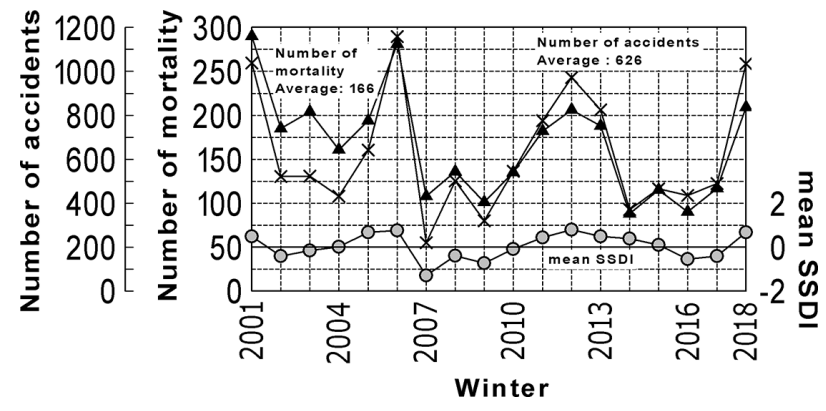

Fig. 1. Number of snow and ice-related accidents $(\times$ marks), and mortalities (black triangles) for each winter season. The seasonal snow depth index (SSDI; Nakai, 2015) for each winter is also shown. The abscissa is the winter season indicated by the year that includes New Year's Day (e.g., 2001 indicates winter 2000/2001). The statistics of accidents and mortalities were from October (2002 (Hokkaido), 2011)/November (2001, 2003-2010, 2012-2013)/ December (2002 (except Hokkaido), 2014-onward) to April (2003-onward)/May (2001-2002). The SSDI was derived from the data from October to April.

information presented in Fig. 1 also underlines the continuing importance of basic observations and analyses in mitigating snowfall-related mortalities.

Close attention should be paid to the occurrence of concentrated heavy snowfall (Nakai and Kumakura, 2007; Motoyoshi and Nakai, 2012; Nakai and Yamaguchi, 2012), which can cause unexpected and sudden snow and icerelated disasters, such as, the heavy snowfall and blizzards in February 2010 in Niigata City (Sato et al., 2012c), heavy snowfall and avalanches in December 2010 in the San'in District (Nakai and Yamaguchi, 2012), and heavy snowfall in January and February 2018 in the Hokuriku District. These disasters were related to abnormally heavy snowfall in cities in the plains area adjacent to the Sea of Japan, as shown in Fig. 2.

The heavy snowfall experienced in the Kanto District and Yamanashi Prefecture of Japan, caused by extra-tropical cyclones passing along the southern coast of Japan in February 2014 (hereafter referred to as H26 heavy snowfall), highlights the importance of preparation against snow and ice-related disasters, not only in areas that often experience snowfall, but also in areas with only occasional snowfall (NIED, 2016). It has been noted that many avalanches that occur following snowfall delivered by an extra-tropical cyclone can be related to a weak layer of snow aggregates composed of unrimed crystals (Nakamura et al., 2014). Unrimed crystals have been observed several hundreds of kilometers to the north of the surface warm front (Murakami et al., 1992; Ishizaka et al., 2015). Colle et al. (2014) observed primarily plates and dendrites with little to no riming in the western quadrant of the comma head. Araki and Murakami (2015) conducted a numerical simulation of the microphysical structures in precipitating clouds of the H26 heavy snowfall. They showed that the coastal front and the seeder-feeder mechanism were important factors driving

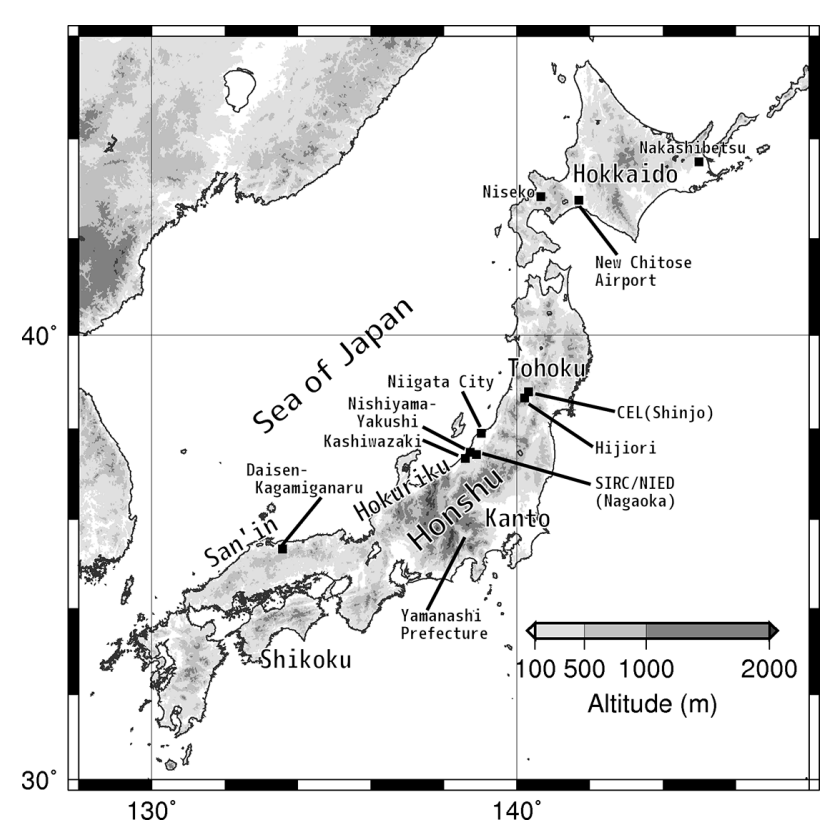

Fig. 2. Locations and names of the observation sites and areas related to selected snow and ice-related disasters. Note that only the names referred to in this paper are shown.

the increase in snowfall during the H26 heavy snowfall. However, the growth process of unrimed aggregates in the cloud system of cyclones has not been thoroughly documented up to this point.

The H26 heavy snowfall also caused damage to buildings due to the accumulation of snowpack with high density and water content on roofs (NIED, 2016). Disasters related to significant amounts of wet snow often occur in snowy areas, as well as in areas that have seen only occasional snowfall in recent years. Examples of such events include the closure of runways of New Chitose Airport in the Hokkaido District in February 2009, the electrical power failure in Niigata City in December 2005 and February 2010, caused by snow accretion, and the electrical power failure and related disruption of communication lines in the eastern Shikoku District in December 2014. The distribution and type of snow and ice-related disasters may change as the climate changes. For example, disasters related to wet snowfall may increase on Honshu Island and even in colder areas such as the Hokkaido District in response to long-term warming trends. Therefore, empirical countermeasures against snow and ice-related disasters are not necessarily effective. A question arising from this situation is what information the scientific and technological community should provide on snow and ice-related disasters to assist in the improvement of structural countermeasures, such as avalanche control fences, and non-structural countermeasures, such as avalanche patrols, organization of snow removal activities, and evacuations.

To solve this problem, the Snow and Ice Research Center of the National Research Institute for Earth Science and Disaster Resilience (SIRC/NIED) has been 
engaged in research on snow disasters through the modeling of snow processes based on both observations and laboratory experiments. The SIRC/NIED has constructed the Snow Disaster Forecasting System (SDFS) to provide information on snow and ice-related disasters. The basic concepts behind the SDFS are described in Sato (2004), while Iwamoto et al. (2008) and Nakai et al. (2012) have described the system in more detail. The system has the capability to predict avalanche potential, visibility in blowing snow, and snow conditions on roads. Results of many observations using the X-POL radar (Iwanami et al., 1996) at SIRC/NIED (Nagaoka), and the Snow and Weather observation Network (SW-Net) ground snow and weather observation network (Yamaguchi et al., 2007, 2011), and basic experiments in the Cryospheric Environment Simulator (CES; Abe and Kosugi, 2019) at the Shinjo Cryospheric Environment Laboratory (CEL) of SIRC/NIED (Shinjo) were used for the construction of the SDFS. New factors, such as the dry snow metamorphism (DSM) factor (Hirashima et al., 2011) and the ejection factor for blowing snow particles (Sato, 2004) were adopted for modeling as part of the SDFS. A meteorological model with a resolution of about $1 \mathrm{~km}$ and snowpack and snow disaster models with resolutions of about $10 \mathrm{~m}$ (or for point prediction) were coupled. All models composing the SDFS are connected and can be executed automatically (Nakai et al., 2012). During its experiments, the SDFS has provided real-time predictions to registered users twice daily (Fig. 3). A survey of the users has shown that the SDFS has the potential to provide useful predictions for decision making, although improvements with regard to accuracy and usability are still required.

However, our understanding of many processes requires improvement. Examples include the growth of falling snow particles, evolution of the blowing snow layer, and snow metamorphism. Research on these processes will improve the prediction of snow and icerelated disasters, e.g., the prediction of unrimed falling snow crystals, which may cause avalanches. Likewise, more work should focus on the relationship between wet snowfall and snow accretion, especially on the growth process of an accretionary snow body on an arbitrary object in relation to various meteorological conditions. It is also important to improve estimates of the errors involved in such predictions. Moreover, the survey has indicated that registered users of the SDFS need realtime information on snow and ice-related disasters. However, to provide such information to local governments and the public, a framework of operational forecasting and disaster mitigation using the information should be constructed. To this end, it is important for users to recognize the utility of the information by providing successful examples of disaster mitigation.

An overview of the progress of SIRC/NIED research tackling these problems is presented in this paper. A new project, the "Study on Advanced Snow Information and
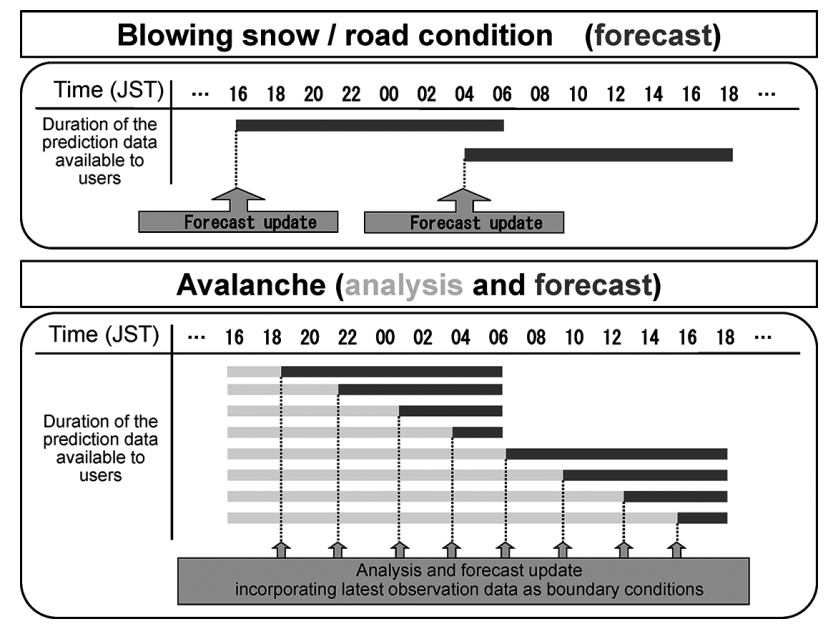

Fig. 3. Scheduling of prediction information updates for the SDFS. The bars indicate the duration of the prediction data available to users at the time on the left end of the dark gray part of each bar. The light gray bars indicate observation-based information, while the dark bars indicate forecasts. Time is expressed in Japan Standard Time (JST).

its Application to Disaster Mitigation (ASDIM)", was started during the financial year of 2011. The configuration and content of the project is described in section 2 . The construction of a cooperative relationship for operational forecasting is given in section 3 . Section 4 summarizes the achievements and future direction of the project.

\section{Project overview}

\subsection{Project configuration}

This research is composed of two parts: (A) research on advancement of falling snow and snow-on-ground information, and (B) development of a real-time snow and ice-related disaster prediction method (Fig. 4). The purpose of (A) is to develop advanced snow information, while that of (B) is to apply the advanced snow information to disaster mitigation. To address these aims, we 1) constructed a new observation system to acquire the data required for analyses of the characteristics and growth of snowfall particles, 2) introduced state-of-the-art electronic technologies to analyze the microstructure of snowpack, 3) transferred the observation data on-line to the SDFS, 4) improved numerical models comprising the SDFS, and 5) started to develop a geographic information system (GIS)-based, on-line, "Real-time Hazard Map (RHM)" and conducted applied experiments in cooperation with local governments and road administrators.

\subsection{Observations and modeling}

In regards to $(A)$, we have constructed the Concentrated Snowfall Monitoring System (CSMS) composed of a polarimetric weather radar (named here as the MultiPhase Precipitation (MP2) radar) and several ground 


\section{Study on Advanced Snow Information and its Application to Disaster Mitigation (ASDIM)}

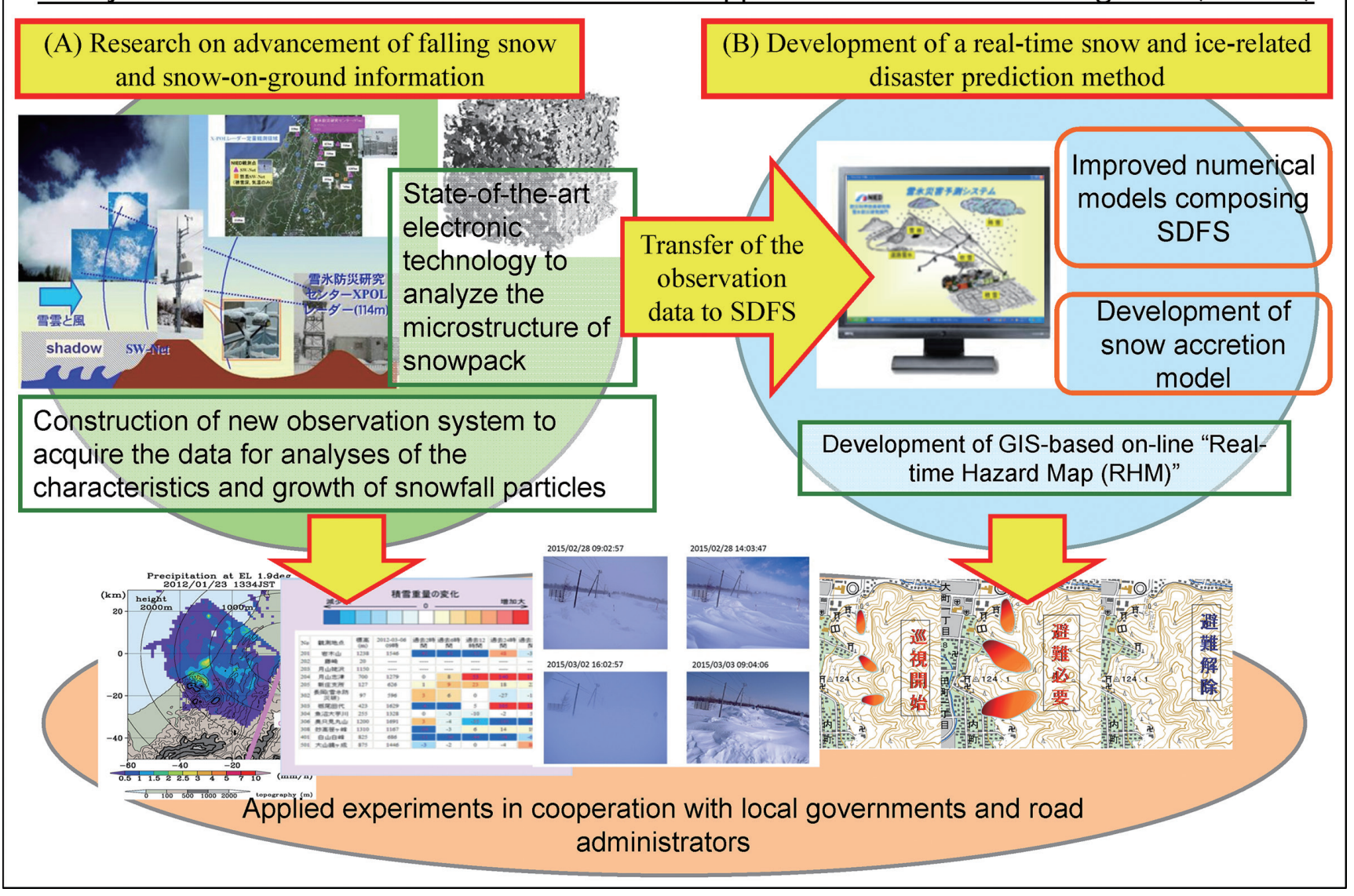

Fig. 4. Conceptual model of the "Study on Advanced Snow Information and its Application to Disaster Mitigation (ASDIM)" project.
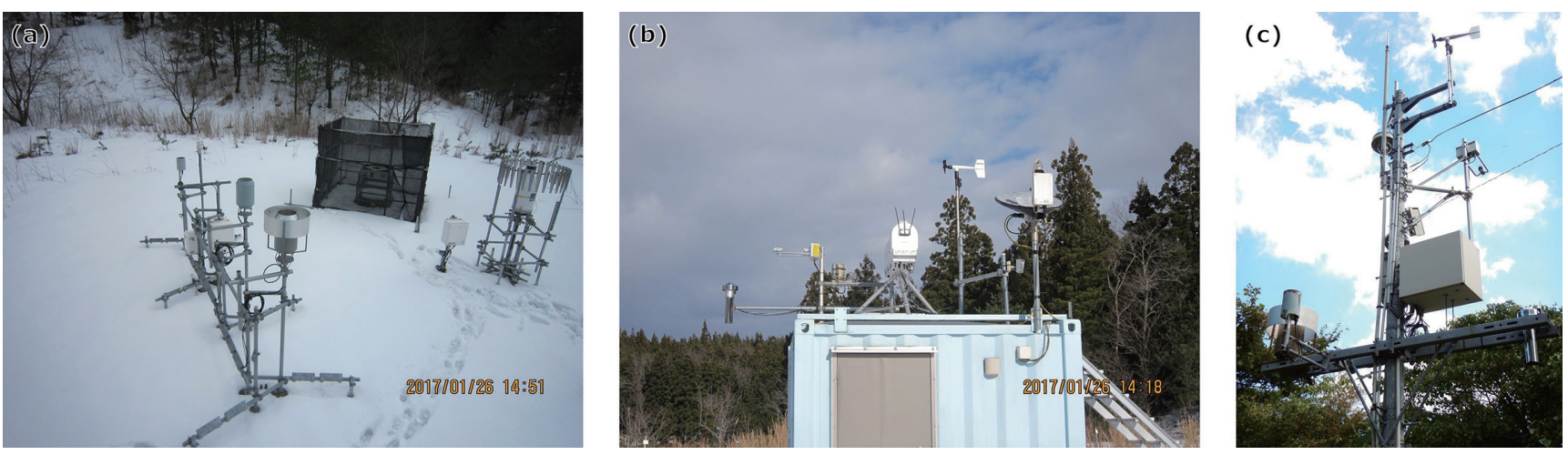

Fig. 5. (a) Precipitation gauges and wind-protected 2DVD at the SPLine-f2 Kashiwazaki site. An Alter wind shield is attached to the Geonor T-200B weighing gauge. The Geonor T-200B gauges at the other two SPLine-f sites are equipped with a single Alter wind shield and a double-fence intercomparison reference (Goodison et al., 1998). (b) Facilities on the roof of the housing container of the Kashiwazaki site. (c) The SPLine-s2 Nishiyama-Yakushi site.

observation sites (named as the Snow Particle observation Line (SPLine)) for monitoring of the occurrence of heavy snowfall causing disasters. The CSMS observes radar polarimetric parameters and falling snow particles on the ground simultaneously. The basic concept of the CSMS is the near-real-time estimation of the distribution of precipitation and type of falling snow particles within the observation range of a polarimetric weather radar referring to ground site observations. This combined analysis will improve the estimation of the distribution of snowfall. Details of the MP2 radar and the SPLine site are given by Yamashita et al. (2019). There are two types of SPLine sites. One is the full-specification site (F-site, Figs. 5ab) equipped with facilities for the observation of ground falling snow particle characteristics and the environment on the ground and in the lower troposphere. These facilities include, for example, a Two-Dimensional Video Disdrometer (2DVD; Kruger and Krajewski, 2002; Schönhuber et al., 2007), a Geonor T-200B weighing gauge (Bakkehøi et al., 1985; Duchon, 2008), and an MP-3000 A 
microwave radiometer (Solheim et al., 1998; Ware et al., 2003). The other is the simple specification site (S-site, Fig. 5c), equipped with a Thies Laser Precipitation Monitor (Bloemink and Lanzinger, 2005; Lanzinger et al., 2006; Brawn and Upton, 2008), Tamura SR-2 (Tamura, 1993), thermometer and hygrometer in a ventilated radiation shield, wind sensor (either ultrasonic or mechanical), and a tipping-bucket precipitation gauge. The purpose of the F-site is to obtain reference data for precise analyses of falling snow particles and precipitation amounts. F-sites yield large amounts of data that require manual on-site data collection, although they are connected to the internet using cellular phones to monitor the status of facilities. Some of the facilities of the F-site require careful maintenance for accurate measurements, and are not suitable for operational use. The purpose of the S-site is to assess the functionality of snowfall particle observations in operational use. We are making various observations using F-sites, which will lead to the proposal of an operational observation and analysis system for the estimation of the current hazard of snow and ice-related disasters using data via an on-line data acquisition system from observations based on the S-site specifications.

We also improved the schemes in some of the models comprising the SDFS. The SNOWPACK model is a one-dimensional model predicting the various physical parameters of layered snowpack (Bartelt and Lehning, 2002; Lehning et al., 2002a, 2002b). The Japan Meteorological Agency (JMA) nonhydrostatic model (JMA-NHM; Saito et al., 2006) is used for the prediction of the meteorological fields. The JMA-NHM is double-nested with the JMA Meso-Scale Model (MSM) operational forecast data (http://www.jma.go.jp/jma/en/Activities/ nwp.html) as initial and boundary conditions. The surface meteorological variables from JMA-NHM output and SWNet observations are used as inputs of the SNOWPACK model in the SDFS (Nakai et al., 2012). The SNOWPACK model is used to evaluate and predict the characteristics of each layer of snowpack, e.g., grain type, grain size, density, temperature, liquid water content, and shear strength. Improvements have been made to SNOWPACK by SIRC/NIED during the ASDIM project, specifically to reflect the characteristics of snow observations in Japan. To express continuous variations of shear strength due to the transition process from rounded grains to faceted crystals, Hirashima et al. (2009) introduced the DSM factor in the expression of shear strength as a function of water vapor transport. To improve the scheme to calculate non-uniform water transportation in snow cover (preferential flow), cold room experiments were carried out (Katsushima et al., 2013; Avanzi et al., 2016), and the multi-dimensional water transport model was developed based on these results (Hirashima et al., 2014, 2017). A comparison of the laboratory results and those obtained from the water transport model is shown in Fig. 6. This experiment showed that liquid water ponded at the interface of fine over coarse snow layers due to the capillary barrier effect. This effect is reproduced by the water transport model fairly well.

In regards to (B), we have made the following improvements in the prediction of snow and ice disasters made using the SDFS. We developed a sequential correction technique for SDFS predictions using observational data. Ground snow conditions reported by a local government were used to modify the boundary conditions of the SDFS (Sato et al., 2012c). SW-Net and
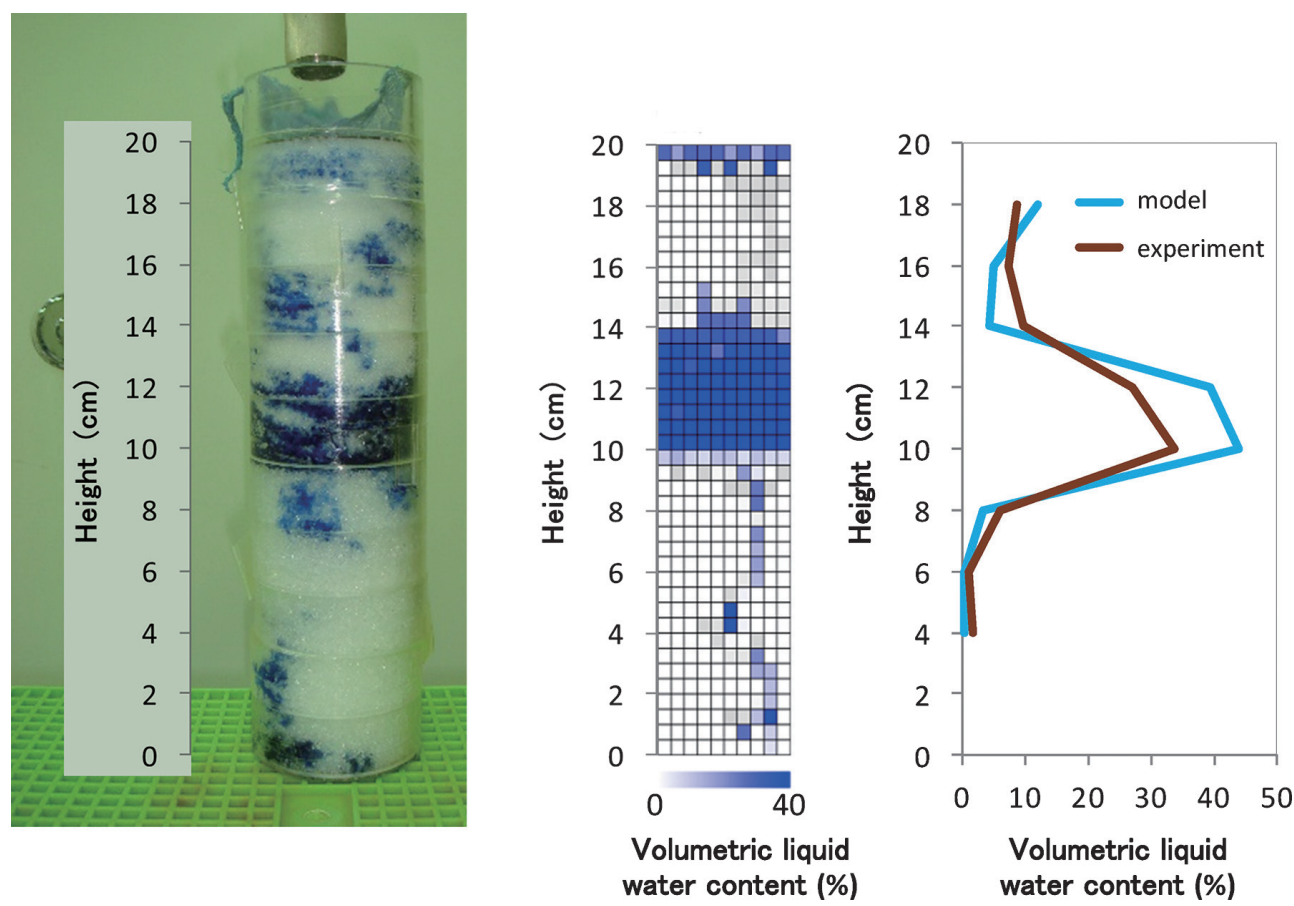

Fig. 6. Comparison of the results from the multi-dimensional water transport model and a laboratory experiment on the formation process of preferential flow. 
other observations (temperature, relative humidity, wind speed and direction, downward shortwave and longwave radiation, precipitation amount, and snow depth) were used to update the snowpack stability prediction, as shown in Fig. 3. Prediction time was extended by increasing the computation power and using new JMA MSM forecast data. The previous SDFS had connected numerical prediction models for meteorological variables, snowpack characteristics, avalanche, drifting snow, and snow on road (Nakai et al., 2012). We have developed a snow accretion prediction model as a component of the SDFS. A new geographic information system (GIS)-based viewing system was developed to support better operational experiments with local governments and road transport administrators, as the end-users. The effects and problems indicated from the use of SDFS in real-time during these cooperative experiments are presented in Section 3.

\subsection{Advanced snow information}

The advanced snow information is a collection of data newly derived by, or adopted in, the methods and algorithms developed in ASDIM. Some of the data were made available on the SIRC/NIED website during winter, and others were used for the applied experiments to test the SDFS.

Optical techniques are useful for automatically detecting the characteristics of falling snow particles. We used a charge-coupled device (CCD) camera system (Muramoto et al., 1989; Muramoto and Matsuura, 1993; Ishizaka et al., 2004; Shiina et al., 2004) and optical disdrometers (Löffler-Mang and Joss, 2000; Battaglia et al., 2010) for this purpose. Typical parameters obtained by these facilities are the horizontal size and falling velocity of each particle. Ishizaka et al. (2013) developed a new analysis method to derive the representative size and falling velocity of precipitation particles from these optical measurements (center of mass flux distribution $(\mathrm{CMF})$ ). Figure 7 provides examples of the analysis results using the $\mathrm{CMF}$ method. The CMF values averaged every $5 \mathrm{~min}$ are plotted as diameter over falling speed. The point colors (indicating the time of observation) showed whether the characteristics of the snow particles changed over time. Using the CMF, for example, the time evolution of representative diameters and falling speeds of graupel (Fig. 7a) and snow aggregates (Fig. 7b) can be detected in 5-min intervals. The CMF method has been used widely to estimate the characteristics of falling snow particles (Kouketsu et al., 2015; Minda et al., 2016; Itado et al., 2017; Masuda et al., 2018). Other observation/analysis methods have been developed, such as the simultaneous measurement of mass, diameter, and velocity of a falling snow particles (Motoyoshi et al., 2016), the parameterization of the liquid water fraction of wet falling snow particles (Misumi et al., 2014), and an algorithm of radar-based solid precipitation intensity using the CMF method and disdrometer measurements (Nakai et al., 2017).

The specific surface area (SSA), defined as the surface area per unit mass, is a parameter of snow that has recently attracted much interest (Domine et al., 2009; Hachikubo et al., 2014). There are four main methods for measuring the SSA of snow: the stratigraphy method (Narita, 1969, 1971); the X-ray method (Coléou et al., 2001); the gas adsorption method (Legagneux et al., 2002); and (a)

2011-01-16 17:00-21:00

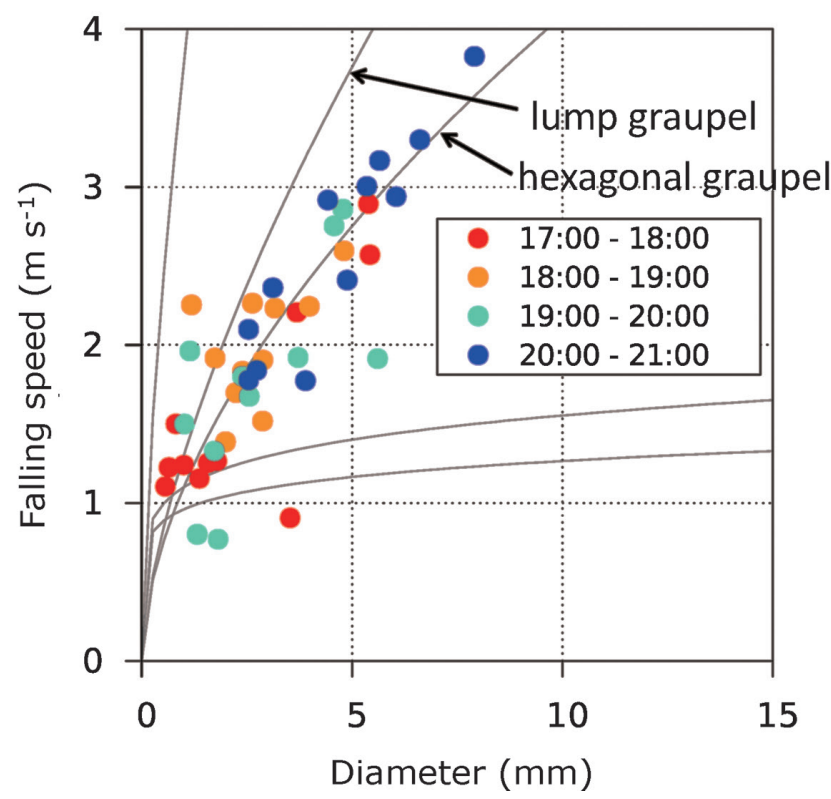

(b) 2011-01-23 09:00-13:00

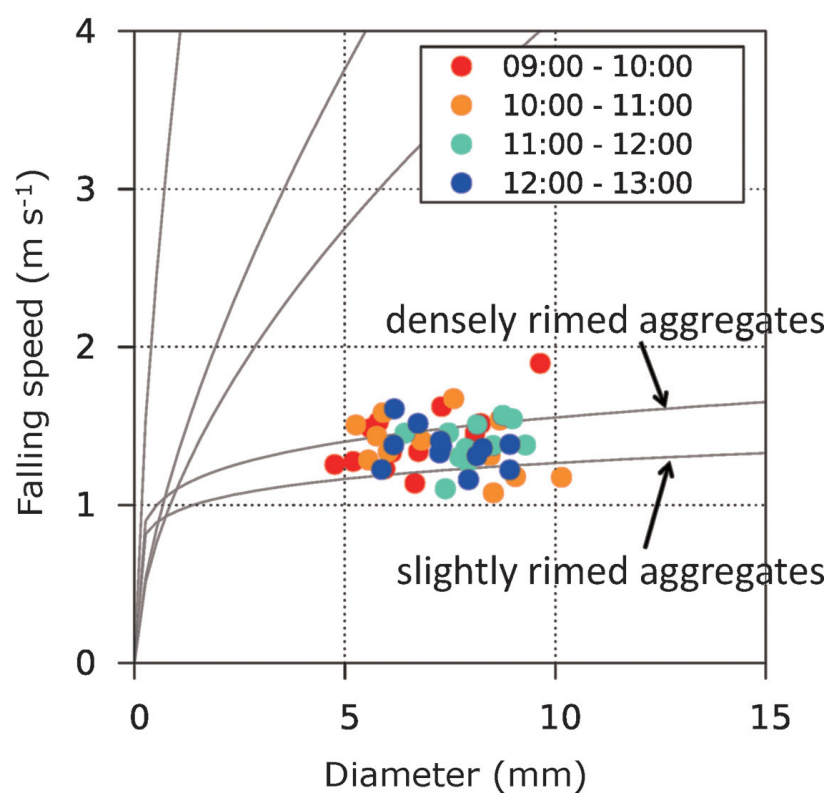

Fig. 7. Examples of the time evolution of representative dimensions and falling speed of snow (a) from small particle to graupel and (b) of snow aggregates during four hours in 5-min intervals derived using the CMF method. The thin gray lines are the size-fall speed relationships typically found for solid precipitation (Ishizaka et al., 2013). 
the near-infrared photography method (Matzl and Schneebeli, 2006). NIED introduced all of these methods during the ASDIM project, and we have evaluated them based on comparisons with each other (Adachi et al., 2014). Moreover, we have tried to improve the SSA measurement methods as applied to wet snow conditions (Yamaguchi et al., 2014; Hachikubo et al., 2017) to expand our understanding of wet snow physics.

Recently, we have focused on the SSA of new snow to describe new snow properties, such as the riming ratio, shape, etc. (Yamaguchi et al., 2016, 2017a). The preliminary results imply that the measured SSA of new snow in Nagaoka has a positive correlation with the wind speed and a negative correlation with temperature, and that the SSA of new snow falling under low-pressure systems typically has smaller values than that falling from snowbands during cold outbreaks. These results will aid the introduction of the characteristics of falling snow particles into the SNOWPACK model, which is an important scheme for predicting weak layers consisting of crystals falling from the clouds of low pressure systems. Validation of the snow-crystal-related weak layer analysis requires observation and survey data from avalanche sites. Many avalanche field investigations on the snow-crystal-related weak layer have been conducted in recent years, for example in February 2014 (NIED, 2016). Data compilation and comparison with the model simulation is important to confirm the utility of SSA for detecting the snow-crystal-related weak layer.

The formulation of snow physics based on the smallscale structure of snow is critical to improving the accuracy of snow disaster forecasting; therefore, highresolution X-ray computerized tomography $(\mathrm{CT})$ and nuclear magnetic resonance imaging (MRI) methods were introduced in the cold room at the CEL. We used a $\mu \mathrm{CT}$ 35 system (SCANCO Medical, Brüttisellen, Switzerland) with a resolution of $1.75-72 \mu \mathrm{m}$ for the X-ray CT. Meanwhile, MRI was performed using a permanent magnet with a static magnetic field intensity of $1.5 \mathrm{~T}$. Adachi et al. (2017) obtained a spatial resolution of $50-400 \mu \mathrm{m}$ in a low-temperature environment by incorporating temperature control devices in the permanent magnet circuit. We applied these technologies to perform several novel experiments related to snow and ice formation. For example, we developed a technique to superimpose a CT image (snow particle distribution, left panel of Fig. 8) and an MRI image (liquid water distribution, right panel of Fig. 8) to analyze the relationship between small-scale snow structure and water distribution (Adachi et al. 2017). The detailed visualization of a mixture of ice, liquid water, and air will be presented in another paper in the near future. Meanwhile, Nakamura et al. (2015) analyzed the physical properties of the weak layer composed of pristine falling snow particles using X-ray CT. This analysis contributes to the microphysical study of this type of weak layer. These results will be introduced into the SNOWPACK model.

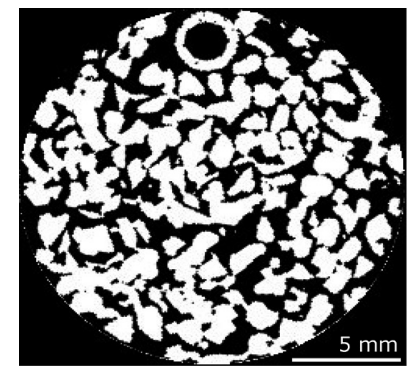

$\mathrm{X}$-ray CT

white : ice

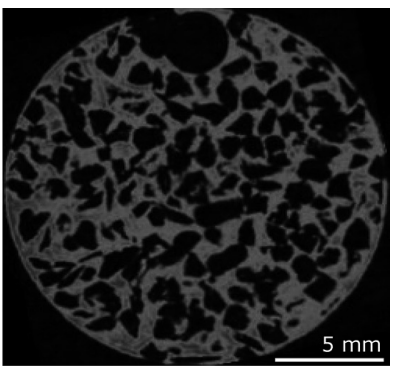

MRI

gray : liquid water
Fig. 8. Example of snowpack visualization by (left) X-ray $\mathrm{CT}$ and (right) MRI. Black areas indicate that the signal strength was below the threshold for the detection of ice (left panel) and water (right panel).

\subsection{Observation-based information and its dissemination} Many snow and ice-related disasters, especially avalanches, occur in mountainous areas. Operational meteorological observation sites of the JMA and local governments tend to be located at relatively low elevations. Therefore, it is important for mitigation of snow and ice-related disasters to evaluate solid precipitation amounts in mountainous areas. We have monitored snow depth, snow weight, and temperature and other meteorological variables in mountainous areas in Japan by constructing the SW-Net (Yamaguchi et al., 2007, 2011). SW-Net sites are distributed in snowy mountainous areas from Niseko $\left(42.9^{\circ} \mathrm{N}, 140.7^{\circ} \mathrm{E}\right)$ to DaisenKagamiganaru $\left(35.3^{\circ} \mathrm{N}, 133.6^{\circ} \mathrm{E}\right)$. We have made webpages presenting the observed values and snow and ice-related hazard information updated in almost real time available online at the SIRC/NIED website (Fig. 9). A portion of the observed values were used as input data for the real-time snow and ice-related disaster prediction models, as well as provided to the JMA and other organizations. We also provided the CMF (Section 2.3) calculation algorithm for the development of an operational government winter precipitation estimation program (Itado et al., 2017; Masuda et al., 2018). This is an example of the transfer of technology from SIRC/ NIED to an administrative infrastructure construction activity. Moreover, the advanced snow information described in Section 2.3 has been applied to the information on the SIRC/NIED website. This information includes much new content that aims to allow an easier understanding of the current situation regarding snowfall and snowpack, for example, information relating to likely snow accumulation on rooftops, melting, falling snow particle types, and radar precipitation intensity reflecting near real-time estimation of the type of falling snow particles (Fig. 9).

\subsection{Development of real-time hazard map technology}

The SDFS, predicting snowpack stability, visibility in snowy conditions, and snow on roads, has been improved 

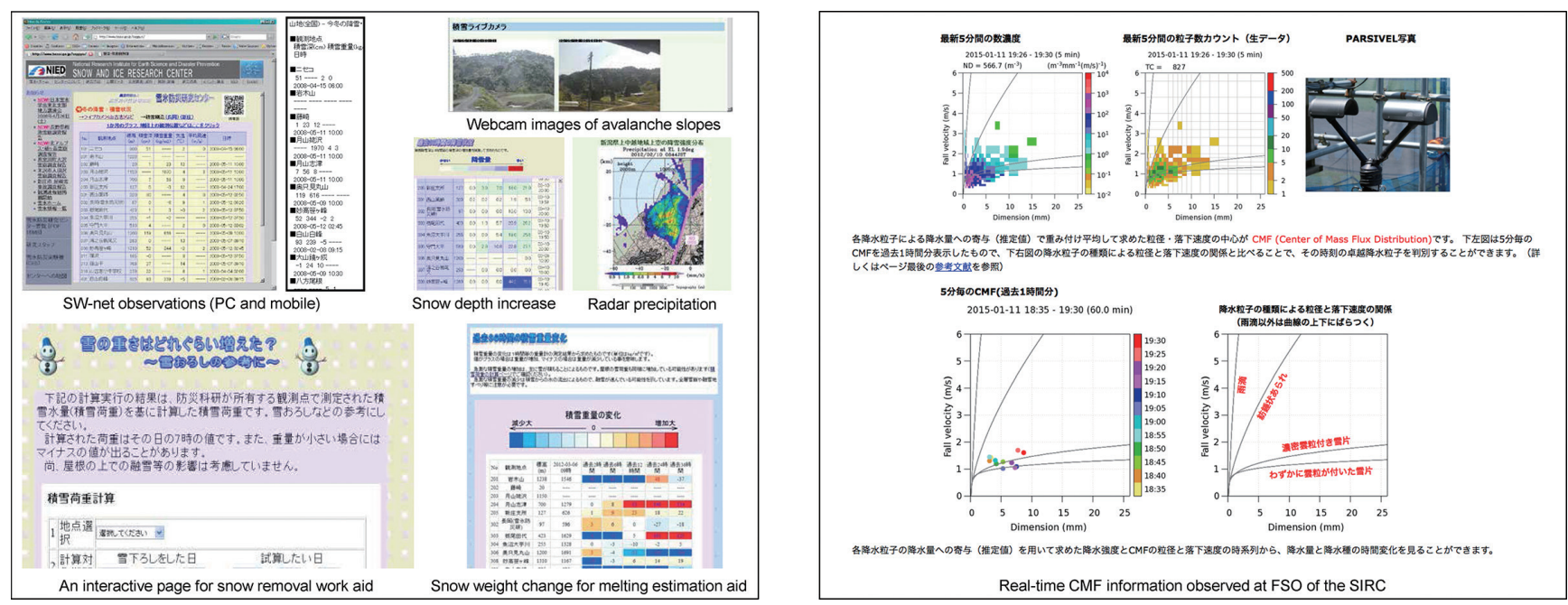

Fig. 9. Examples of open-access (left panel) observed values and snow and ice-related hazard information, and (right panel) advanced snow information available on the SIRC/NIED website (http://www.bosai.go.jp/seppyo/, Japanese only).

through applied experiments on snow and ice-related disaster prediction in cooperation with local governments and road transport administrators (Nakai et al., 2012). The usefulness of the predictions was confirmed by applying the predictions to traffic control operations and snow-removal scheduling in parallel with operational judgment processes. Several problems to be solved arose simultaneously. How should we systemize the process that we use for disaster mitigation? How can we estimate the area affected by an avalanche, as well as predict their occurrence? The hazards that are not yet covered by the SDFS, such as accreted snow, should also be included. The SIRC/NIED developed an RHM, displaying appropriately updated areas affected by various snow and icerelated hazards, as an answer to some of these problems. The main target of this technology is the mitigation of disasters caused by avalanches, blizzards, and snow accretion.

The avalanche RHM technology was developed by coupling the SNOWPACK model and an avalanche dynamics model. First, the initial volume of the predicted avalanche is estimated using the simulation results of SNOWPACK. Then, the area predicted to be damaged by the avalanche is estimated using a three-dimensional avalanche dynamics model. The avalanche RHM was validated by comparison with the results of avalanche field surveys. Currently, NIED does not have an original avalanche dynamics model; therefore, we have used several avalanche dynamics models, e.g., TITAN2D (Pitman et al., 2003, 2013), RAMMS (Bartelt et al., 1999; Christen et al., 2010), and a non-Newtonian fluid model (Oda et al., 2011) developed through collaborations between universities and institutes. For example, the nonNewtonian fluid model was applied to an avalanche that generated debris that reached National Road Route 112, and the results showed that the model can effectively evaluate the area affected by avalanche debris by taking into account the local topography and vegetation
(Yamaguchi et al., 2017b). This method has been used for analyses of avalanches that occurred in relation to falling snow crystals associated with low-pressure systems in 2014 (Fig. 10) and 2017 (Oda et al., 2017). In addition, the TITAN2D model was applied to estimate the extent of damage caused by an avalanche in Langtang, Nepal, induced by the 2015 Gorkha Earthquake (Ito et al., 2016) and used to construct a hazard map (Nishimura and Abe, 2011).

Comparing these methods could help improve the models. Therefore, we have established an avalanche observation site (Hijiori avalanche observation site; See Fig. 2) near Shinjo, and have accumulated data on avalanche dynamics using a web camera system. These data should contribute to the improvement of the parameter treatment in the models, such as the bed friction coefficient, the coefficient of kinematic viscosity, etc. Through these studies, the accuracy of avalanche RHM has been improved.

For the snow accretion RHM, surface meteorological conditions of significantly wet snow were examined with an analysis of past events of significant snow accretion and field observations (Sato et al., 2012a). Meanwhile, an experimental technique to generate realistic snow accretion in the cold room of the CES was developed (Sato et al., 2012b). This technique enabled successful experiments on the dependency of the growth speed, shape, and density of the accreted snow body on meteorological conditions (Sato et al., 2013). A snow accretion model was developed based on the results of these experiments. We developed a snow accretion RHM showing the extent and amount of snow accretion on a GIS map using the snow accretion model (Fig. 11). For validation, a comparison was made between the output of the snow accretion RHM and observations, and knowledge of the prediction accuracy was compiled for future improvement.

The blowing snow RHM was developed by integrat- 


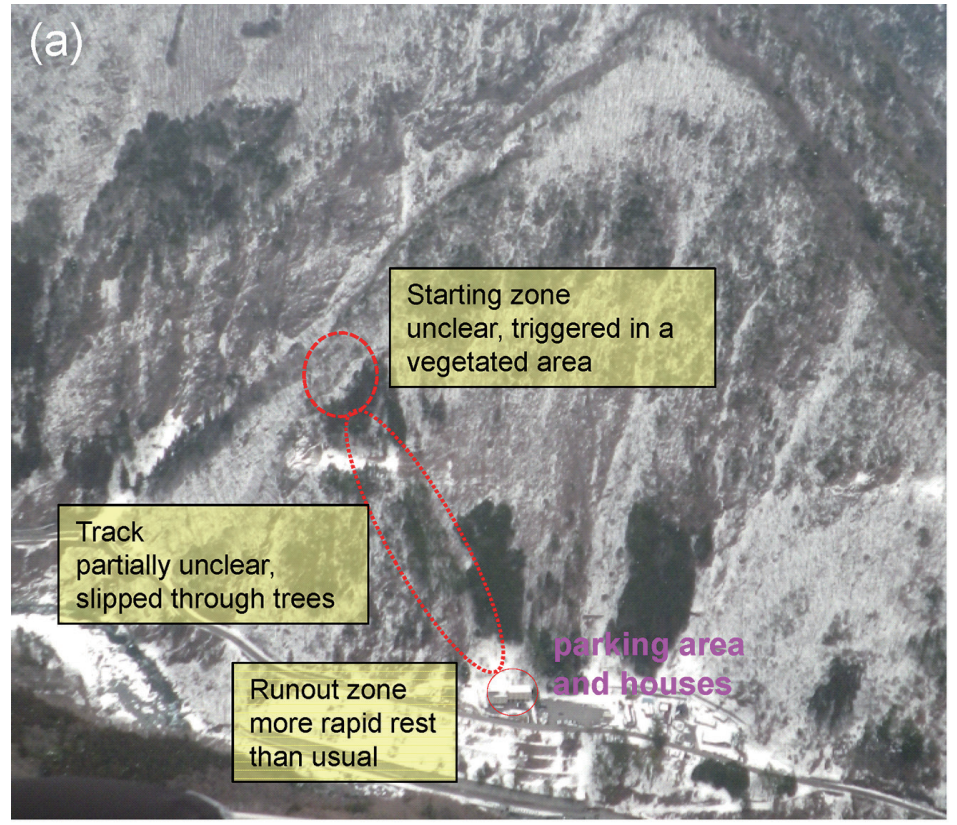

(Photo taken on March 10, 2014) (b)
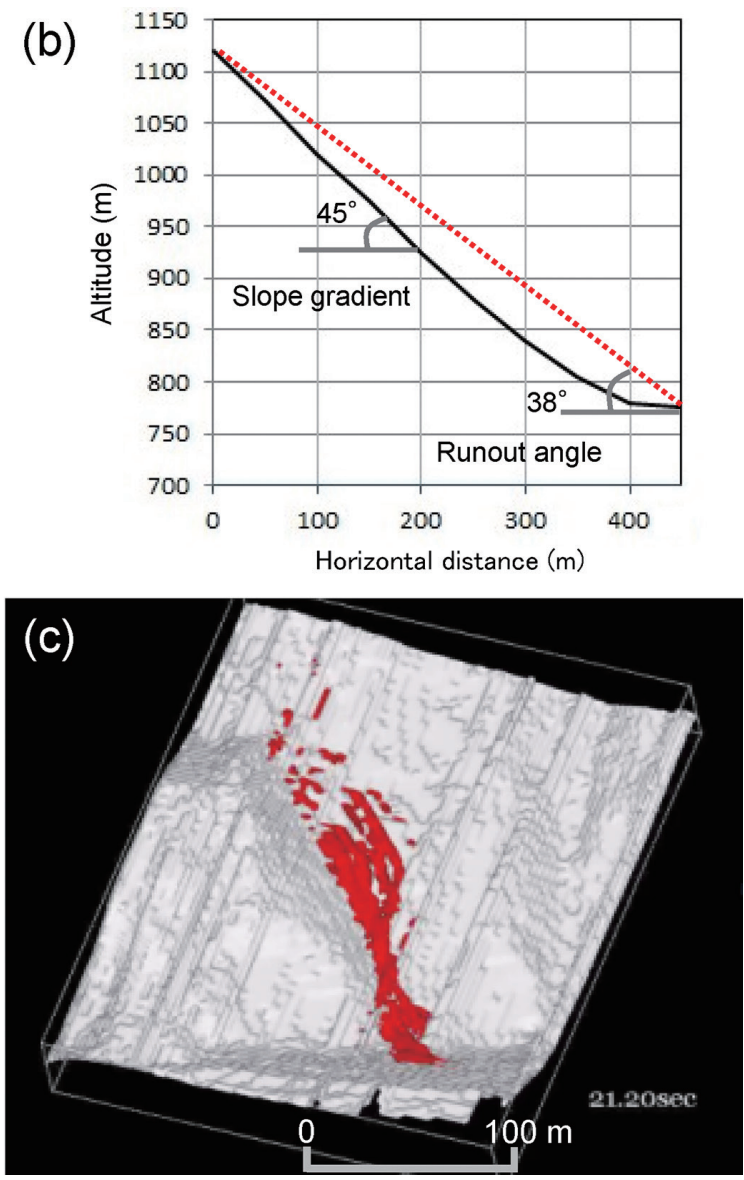

Fig. 10. Avalanche caused by snowfall deposited by an extra-tropical cyclone in Hayakawa Town, Yamanashi Prefecture in February 2014. (a) The avalanche path. The thick dashed, thick dotted, and thin solid circles indicate the starting zone, track, and runout zone of the avalanche, respectively. (b) Longitudinal cross-section along the path shown in (a). (c) Reproduction of the avalanche by a three-dimensional kinematic model.

ing a blowing-snow prediction model, visibility estimation (Sato et al., 2012c; Nakai et al., 2012), and a snow drift potential model. The blowing-snow prediction model predicts the profile of blowing snow from meteorological conditions, taking surface snow conditions into account. Visibility is estimated from the blowing snow profile and snowfall intensity from the JMA-NHM calculations and the JMA MSM forecast data. The blowing snow RHM showed the best results in terms of societal application among the RHMs developed in the SIRC/NIED, and was shown to be capable of deriving information useful for decision-making (e.g., regarding road closure) through applied experiments in Niigata City, Tohoku District, and Hokkaido District (Sato et al., 2012c).

\section{Building cooperative relationships}

Figure 12 presents an example of a practical applied experiment of the blowing snow RHM with a local government. When visibility is predicted to decrease below a prearranged threshold, an e-mail is sent to the cell phones of personnel in charge. The personnel who receive the e-mail check the distribution of the predicted visibility by using the SDFS viewer and identify points of possible disaster. Then, they go to the specified areas and take the appropriate countermeasures (e.g., traffic regulation) based on an in-situ final decision (Sato et al., 2012c). It is important to note that the judgment is made based on an in-situ observation conducted by the personnel, not on the e-mail alert or predicted visibility alone. This arrangement enables early implementation of countermeasures while minimizing the likelihood of decision making based on bad data or poor judgements.

Another experiment applying the blowing snow RHM to the eastern Hokkaido District was conducted (Nemoto et al., 2015, 2017). It has been carried out in cooperation with the Nakashibetsu town office, and has been on-going since winter 2013/2014. The aim of the experiment was to test the effectiveness of countermeasures deployed as a result of using the output of the blowing snow RHM, as well as blowing snow monitoring for the nowcasting of blizzard risk using web cameras. The blowing snow RHM was able to reproduce the period of occurrence and the distribution of strong blowing snow (NIED, 2016, pp. 69-74). When hazardous blizzards were anticipated, researchers of SIRC/NIED provided advice based on the prediction and monitoring data to the staff member of the Nakashibetsu town office on the likely intensity, duration, and accuracy of predicted blowing snow, and on the usage of the prediction for 


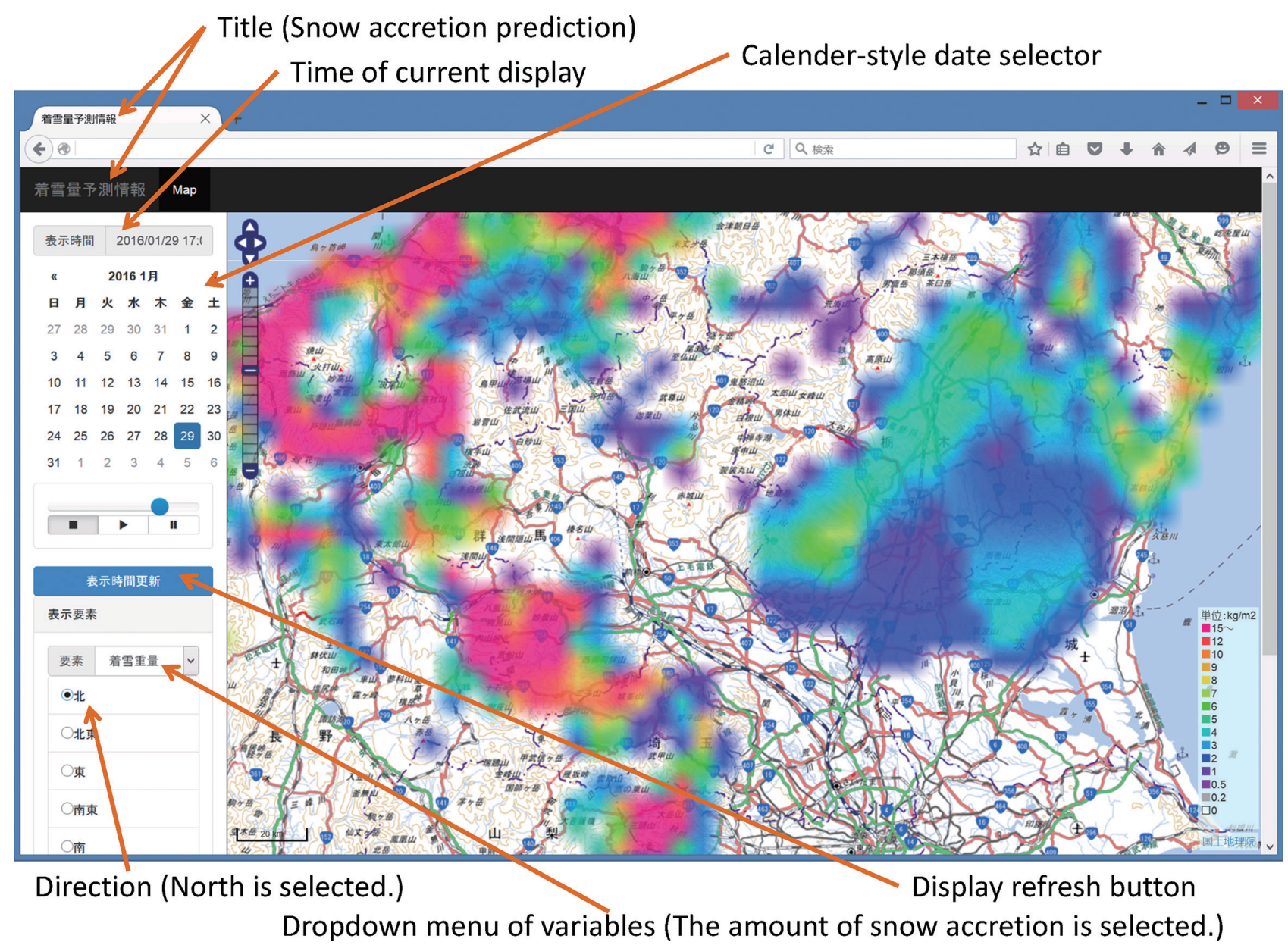

Fig. 11. Example of the snow accretion RHM display. The possible maximum amount of snow accretion on a ground object facing northward $\left(\mathrm{kg} \mathrm{m}^{-2}\right)$ is shown as different colors on the GIS-based system. The display area can be scrolled and zoomed using mouse gestures.

mitigation measures. The effectiveness of this process was examined by comparing the prediction with information on actual traffic disruption and related industrial damage (e.g., the interruption of shipping of milk from farms) provided by the Nakashibetsu town office.

Several low-pressure systems that passed over the eastern Hokkaido District brought record heavy snowfall during winter 2014/2015. The daily snowfall depth exceeded $20 \mathrm{~cm}$ five times, and the maximum snow depth $(156 \mathrm{~cm})$ was much larger than the 26-winter (1985-2010) average $(72 \mathrm{~cm})$. The heavy snowfall overwhelmed snow removal work and caused the cancellation of various social activities. Figure 13 shows an example of a visibility prediction for February 15, 2015. The blowing snow RHM prediction was generally adequate around Nakashibetsu town for the outbreak and duration of heavy blowing snow (NIED, 2016, pp. 119-122). The strength of blowing snow was underestimated in cases of snowstorms that occurred at temperatures of around $0{ }^{\circ} \mathrm{C}$ during this winter. This suggests that problems remain in the models regarding the entrainment processes over the snow surface at the temperature slightly below the melting point. The web cameras set up on the road shoulder were effective for monitoring visibility and snow drift
(Fig. 14).

A close cooperative relationship between SIRC/ NIED and the disaster prevention section of the Nakashibetsu town office has been built. Moreover, a framework of practical actions to take during severe snowstorms, through collaboration between scientific professionals and town office staff, was constructed. In this collaboration, both the scientists and town office staff actively participated in information exchange and discussion regarding the countermeasures to be used. However, important problems still need to be addressed, including the establishment of a sustainable and community-rooted collaboration system ensuring financial resourcing, and the arrangement and deployment of the collaboration system to surrounding areas that have a risk of disaster related to snowstorms similar to Nakashibetsu town. To address these issues, we started another initiative during the financial year of 2016. As part of this initiative, the experimental collaboration system will be extended to the surrounding areas with the aim of achieving close cooperation with neighboring local governments, and providing more effective winter disaster mitigation in this area based on scientific knowledge. This activity includes the building of a 


\section{Applied experiment of the blowing snow (visibility) RHM}

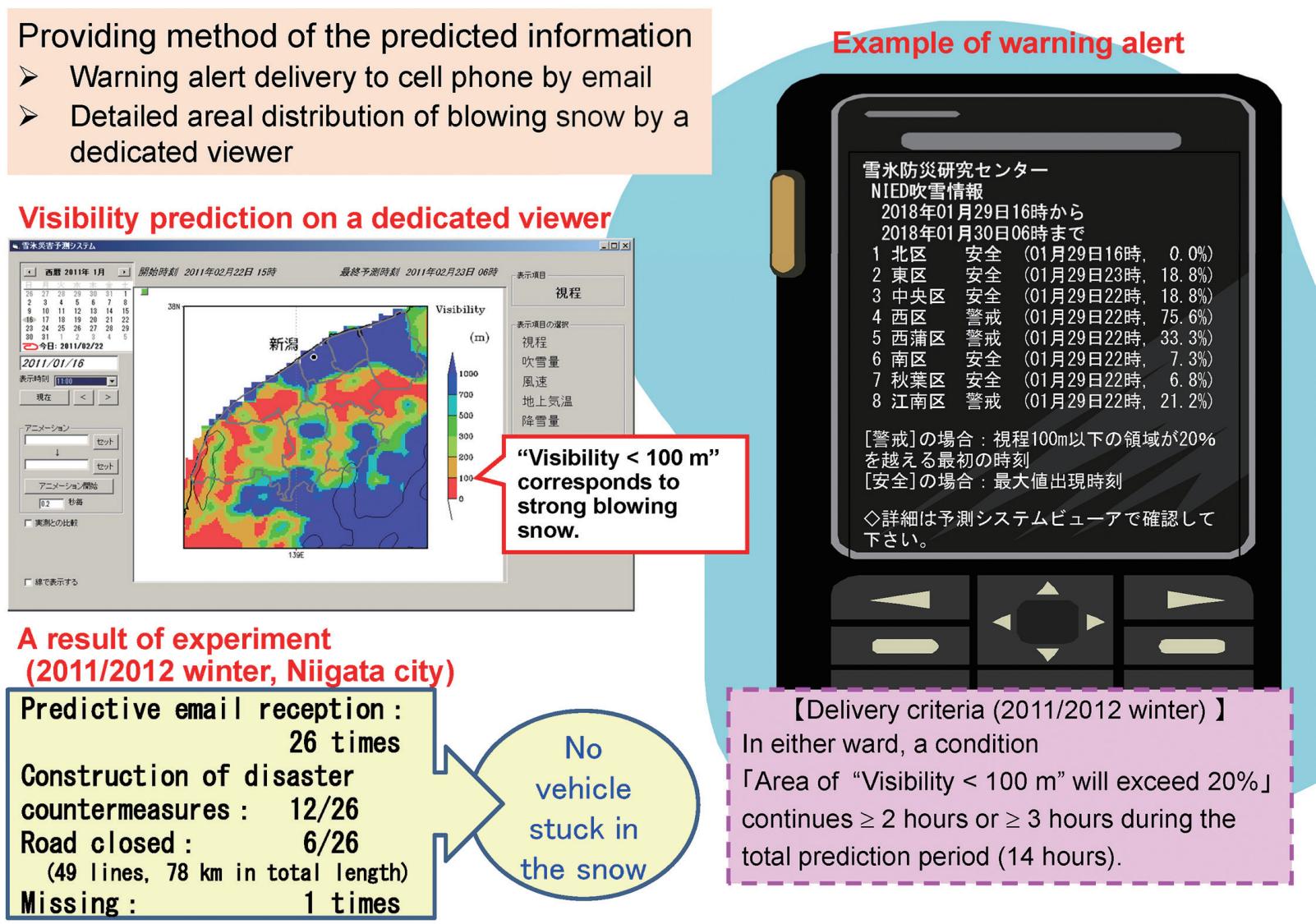

Fig. 12. Arrangement and result of an applied experiment focused on a blowing snow RHM run in conjunction with a local government. The "Example of warning alert" provides an example of the actual e-mail sent to the users from the system.

framework for the construction of a collaboration system between scientific professionals and the local government. An educational initiative on snow and ice-related disasters is also planned to improve the basic disaster mitigation skills of local citizens.

Through these studies comprising the ASDIM project, the SIRC/NIED has developed international partnerships with several institutes. Evidence of these partnerships include a memorandum of understanding with the Institute for Snow and Avalanche Research of the Swiss Federal Institute for Forest, Snow and Landscape (since 2014), a memorandum of cooperation with the Xinjiang Institute of Ecology and Geography of the Chinese Academy of Sciences (since 2015), and a memorandum of cooperation with the National Research Institute of Science and Technology for Environment and Agriculture, France (since 2016). We will continue to develop further international collaborations in the future.

\section{Summary and future direction}

We have developed and examined systems for the monitoring of heavy snowfall and forecast of snow and ice-related disasters to enable more effective deployment of countermeasures to mitigate these events. The prediction system, devised by physical modeling starting from meteorological forecasts, has been shown to be practical for the mitigation of snow and ice-related disasters. The major achievements of the ASDIM project are summarized in Table 1.

The predictions by the RHMs should be used for decision-making processes, as discussed in Section 2.5. The establishment of a collaborative system between scientific professionals and the local government office, introduced in Section 3, is necessary for the effective application of the RHM. Through such a system, improved disaster mitigation may be realized through correct and rapid reactions during a hazardous event, although the forecasting is not perfect. This is a key point of the usage of the RHMs developed in the ASDIM project.

The locations of the SIRC and CEL in snowy areas in Japan are advantageous for the validation of the RHMs, as well as for observations and disaster surveys of snow and ice-related phenomena. To mitigate the problems related to forecasting, such as the growth of errors with the time integration of a forecast model, we have developed a real-time analysis method for falling snow particle type and radar precipitation intensity, and methods and techniques to measure and describe the 


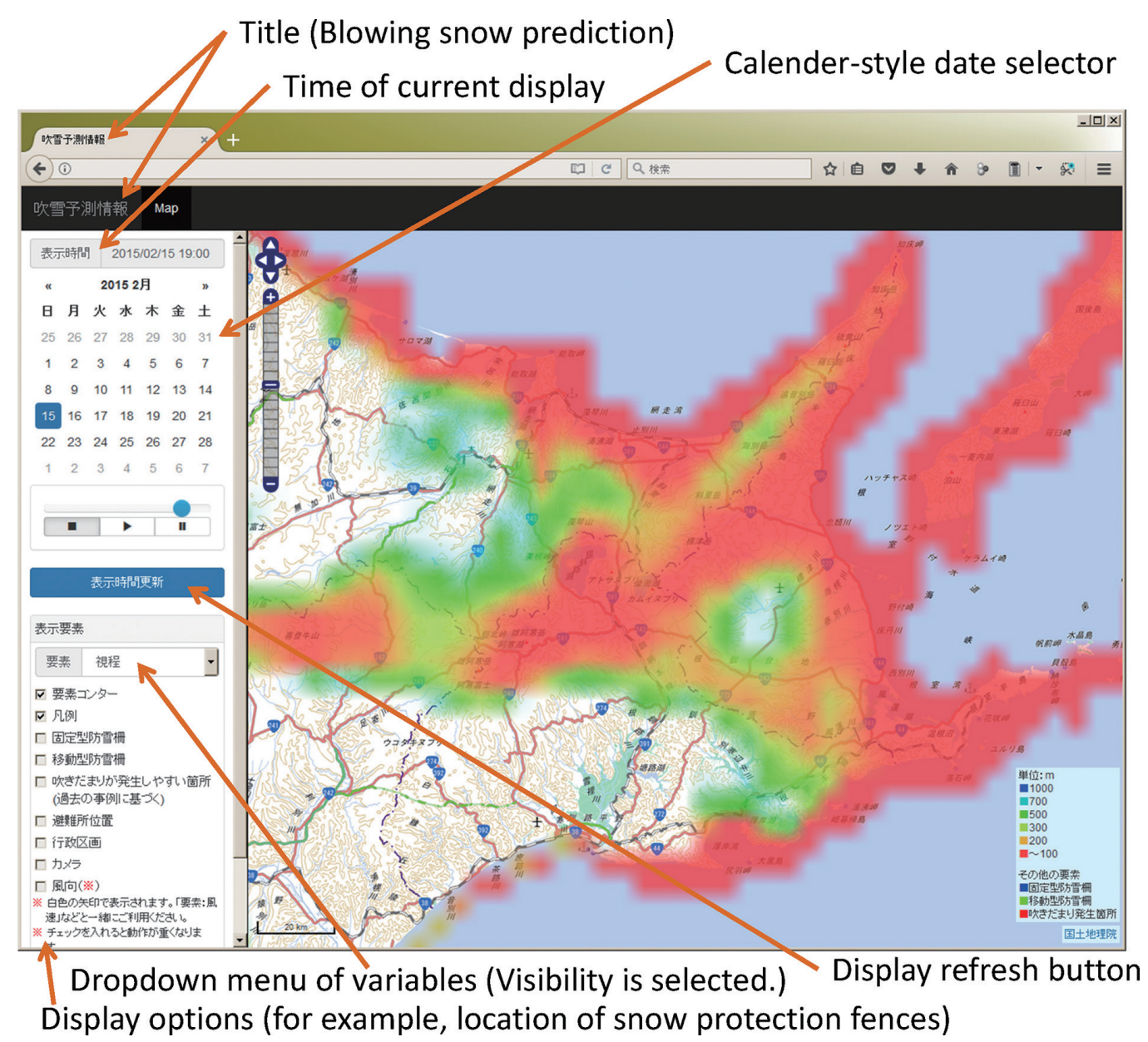

Fig. 13. Example of a visibility (m) prediction display valid for 1900 JST February 15, 2015. Low visibility areas are highlighted by different colors on the GIS-based system. The display area can be scrolled and zoomed using mouse gestures.

microphysical structure of snowpack and falling snow, models of preferential flow of snowpack, snow accretion, and snowdrift. However, the newly developed methods and the SDFS were not fully coupled during the ASDIM project period. Therefore, it is necessary to develop technology and related scientific understanding that will enable the coupling of advanced snow information, realtime monitoring, and prediction of snow and ice-related disasters, which we aim to do in a post-ASDIM project.

Several new parameters (e.g., CMF, DSM factor, and SSA) were introduced to express the state of particles of falling snow and snow on the ground during the ASDIM project. Recently, Hashimoto et al. (2017) introduced new prognostic variables representing depositional growth and riming of ice particles into the JMA-NHM. The microphysical parameters predicted by the new JMANHM can be examined using observation data by calculating the $\mathrm{CMF}$ and SSA. The CMF has also been used for the radar quantitative precipitation estimation (QPE) during the ASDIM project. Meanwhile, polarimetric parameters of dual-polarized meteorological radars can be used for the radar QPE in these years. We are planning to use both types of QPE, because these two methods are independent of each other, and improvement of QPE is expected by using both methods.
The SSA of various types of falling snow particles and snowpack will be derived by direct observations at FSO and using X-ray CT. The SSA and other parameters newly introduced during the ASDIM project will be introduced into the SNOWPACK model. Thus, the SNOWPACK model will be able to reflect information of the detailed shape of falling snow particles into the calculation of snow metamorphism. This new approach will lead to a new method for evaluating risk from numerical weather forecasting of surface avalanches caused by snow-crystal-related weak layers associated with cyclones passing along the southern coast of Japan (Kamiishi and Nakamura, 2018). Evaluation methods of the liquid water fraction of falling snow particles and infiltration in the snowpack were developed during the ASDIM project. These methods enabled the authors to derive better information on "rain on snow", snow weight on the roof, and risk of destruction of buildings by snow.

Newly introduced parameters (i.e., CMF, SSA, liquid water fraction, DSM factor, etc.) and methods of measurement and experiment during the ASDIM project have improved the numerical expression of falling snow particles, snowpack on the ground and roof, blowing snow, and accreted snow bodies. Evaluating the relationships between these parameters and meteorological 
2015/02/28 09:02:57

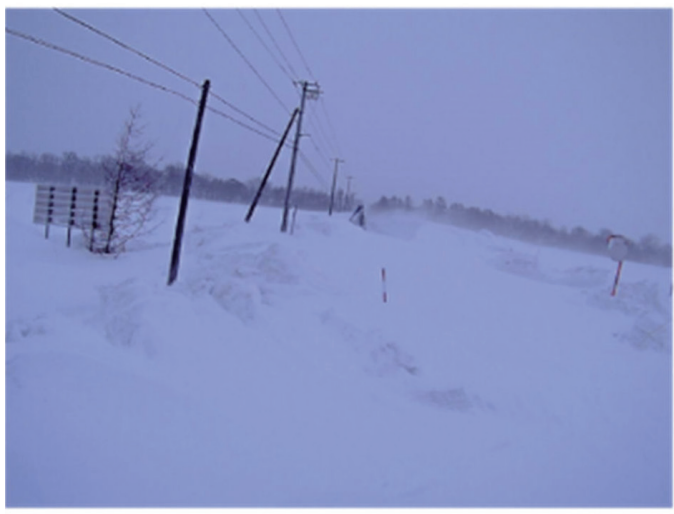

2015/03/02 16:02:57

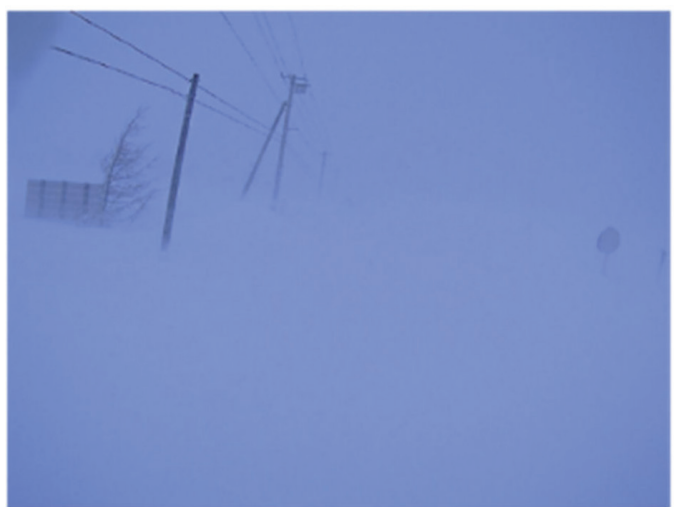

$2015 / 02 / 28$ 14:03:47

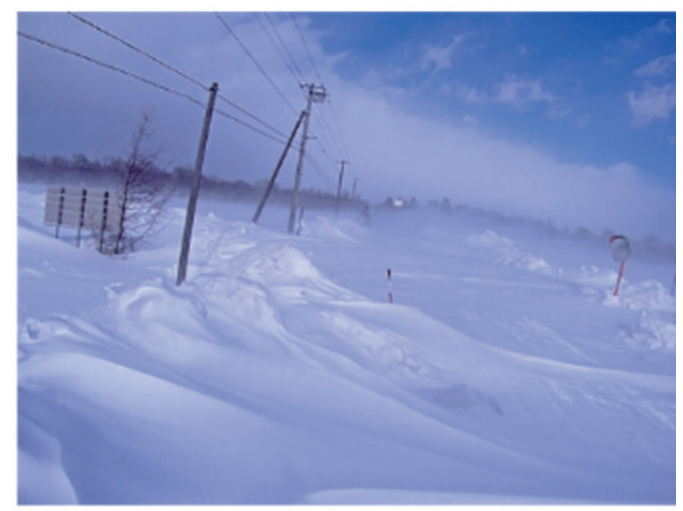

2015/03/03 09:04:06

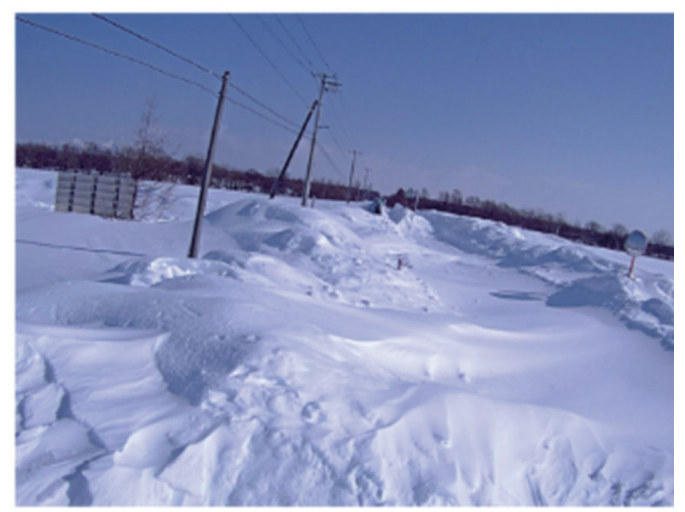

Fig. 14. Images of blowing snow and snowdrifts collected via webcam for snow monitoring in Nakashibetsu town (NIED, 2016).

conditions will improve the performance of the RHMs developed during the ASDIM project. Currently, all RHMs are connected to the JMA-NHM and can run automatically. However, many of their outputs are used separately. Various snow- and ice-related disasters may occur in a sequence corresponding to changes in local meteorological conditions. Thus, the coupling of the RHMs, including the prediction of high-risk disasters, is necessary. Conversion from physical values of the characteristics of snow to suitable alerts is also necessary.

Snow on roofs and road surface change not only under natural conditions but also due to human activities, including heating, spraying of snow melting agents, and snow removal. Therefore, communication with road administrators, local governments, and inhabitants is important to parameterize human activities. The GISbased RHMs have the potential to be integrated into a Web-based platform to promote communication and mutual information exchange for disaster mitigation.

\section{Acknowledgments}

The authors are grateful to an anonymous reviewer and the editor, Dr. Uchida, for their constructive comments, which significantly contributed to improve the manuscript. This research was supported by a management expenses grant for the National Research Institute for Earth Science and Disaster Resilience and Ministry of Education, Culture, Sports, Science and Technology's "Research Project for Supporting to Local Disaster Resilience"

\section{Appendix List of acronyms}

2DVD Two-Dimensional Video Disdrometer

ASDIM Study on Advanced Snow Information and its Application to Disaster Mitigation

CCD Charge-coupled device

CEL Cryospheric Environment Laboratory

CES Cryospheric Environment Simulator

$\mathrm{CMF} \quad$ Center of mass flux distribution

CSMS Concentrated Snowfall Monitoring System

DSM factor Dry snow metamorphism factor

GIS Geographic information system

JMA Japan Meteorological Agency

JMA-NHM JMA NonHydrostatic Model

JST Japan Standard Time

MP2 radar Multi-Phase Precipitation radar

MRI Magnetic resonance imaging

MSM Meso-Scale Model

NIED National Research Institute for Earth Science and Disaster Resilience

QPE Quantitative precipitation estimation

RAMMS RApid Mass Movement Simulation 
Table 1. List of results from the ASDIM project.

Study on Advanced Snow Information and its Application to Disaster Mitigation (ASDIM)

Part (A) Research on the advancement of falling snow and snow-on-ground information

1) Construction of a new observation system and development of related analysis methods

- The CSMS was constructed. The basic concept of the CSMS is the near-real-time estimation of the distribution of precipitation amount and the falling snow particle type within the observation range of a polarimetric weather radar referring to ground site observations (Yamashita et al., 2019).

- Observations made by the SW-Net (Yamaguchi et al., 2007, 2011) and "advanced snow information" are available online at the SIRC/NIED website, including information related to likely snow accumulation on rooftops, melting, falling snow particle types, and radar precipitation intensity, reflecting the particle type.

- SW-Net observational data were provided on-line to the JMA and other organizations.

- A new analysis method to derive the representative size and falling velocity of precipitation particles from optical measurements, the CMF distribution, was developed (Ishizaka et al., 2013).

- Some of the developed methods, including the CMF method, were used for the development of an administrative infrastructure management method (e.g., Itado et al., 2017).

- A simultaneous method of measuring the mass, diameter, and velocity of falling snow particles was developed (Motoyoshi $e t$ al., 2016)

- A parameterization of the liquid water fraction of wet falling snow particles was developed (Misumi et al., 2014).

- An algorithm of the radar-based solid precipitation intensity using the CMF method and disdrometer measurements was developed (Nakai et al., 2017).

2) Introduction of state-of-the-art electronic technologies to analyze the microstructure of snowpack

- High-resolution MRI and X-ray CT were introduced into the cold room at the CEL.

- A technique to superimpose a CT image and an MRI image was developed to analyze the relationship between small-scale snow structure and water distribution (Adachi et al., 2017).

- The SSA of new snow was suggested to be usable as a parameter in the SNOWPACK model (Yamaguchi et al., 2016, 2017a).

Part (B) Development of a real-time snow and ice-related disaster prediction method

3) Improvement of numerical models comprising the SDFS

- Near real-time observation data were used in the SDFS prediction.

- A sequential correction technique for SDFS predictions using observational data was developed (Sato et al., 2012c).

- The DSM factor, a function of water vapor transport, was introduced in the expression of shear strength (Hirashima et al., 2009).

- Multi-dimensional water transport model was developed and preferential flow of snowpack was reproduced (Hirashima $e t$ al., 2014, 2017).

- A snow accretion prediction model was developed as a component of the SDFS.

4) Development of a GIS-based, on-line, "Real-time Hazard Map (RHM)"

- The avalanche RHM was developed by coupling the SNOWPACK model and a three-dimensional avalanche dynamics model (Nishimura and Abe, 2011). The method has been used for the analysis of several disastrous avalanches (Ito et al., 2016; Oda et al., 2017).

- An experimental technique to generate realistic snow accretion in the cold room of the CES (Sato et al., 2012b) enabled experiments on the growth speed, shape, and density of the accreted snow body (Sato et al., 2013).

- A snow accretion model was newly developed and integrated into a snow accretion RHM showing the extent and amount of snow accretion on a GIS map.

- The blowing snow RHM was developed by integrating a blowing-snow prediction model, visibility estimation (Sato et al., 2012c; Nakai et al., 2012), and a snow drift potential model.

5) Applied experiments and construction of a cooperative framework

- The blowing snow RHM was shown to be capable of deriving information useful for decision making through applied experiments with several local governments (Sato et al., 2012c).

- A framework of practical actions to take during severe snowstorms, through collaboration between scientific professionals and the Nakashibetsu town office staff, was experimentally constructed.

- International partnerships with several institutes were developed.

RHM Real-time Hazard Map

SDFS Snow Disaster Forecasting System

SIRC Snow and Ice Research Center

SPLine Snow Particle observation Line

SSA Specific surface area

SSDI Seasonal snowfall depth index

SW-Net Snow and Weather observation Network

X-ray CT X-ray computerized tomography

\section{References}

Abe, O. and Kosugi, K. (2019): Twenty-year operation of Cryospheric Environment Simulator. Bull. Glaciol. Res., 37S, 5365, doi:10.5331/bgr.16SR01.

Abe, O., Nemoto, M., Mochizuki, S., Kosugi, K., Hanaoka, M., Machida, M., Machida, T., Abe, T., Kamiishi, I. and Hirashima, H. (2012): Observations of the avalanche accident occurred on Route 112 and judgment of avalanche safety for 
the surrounding slopes (in Japanese with English abstract and captions). Natural Disaster Res. Rept., 47, 71-82.

Adachi, S., Nakamura, K., Yamaguchi, S. and Abe, O. (2014): Comparison of techniques to measure SSA of snow Influence of analyzable resolutions - (in Japanese). Summaries of JSSI \& JSSE Joint Conf. on Snow and Ice Res., Sept. 20-23, 2014, Hachinohe, P257.

Adachi, S., Yamaguchi, S., Ozeki, T. and Kose, K. (2017): Current status of application of cryospheric MRI to wet snow studies (in Japanese). J. Jpn. Soc. Snow and Ice (Seppyo), 79, 497509 .

Araki, K. and Murakami, M. (2015): Numerical simulation of heavy snowfall and the potential role of ice nuclei in cloud formation and precipitation development. CAS/JSC WGNE Research Activities in Atmospheric and Oceanic Modelling, 45, 4.03-4.04.

Avanzi, F., Hirashima, H., Yamaguchi, S., Katsushima, T. and De Michele, C. (2016): Observations of capillary barriers and preferential flow in layered snow during cold laboratory experiments. The Cryosphere, 10, 2013-2026, doi:10.5194/tc10-2013-2016.

Bakkehøi, S., Øien, K. and Førland, E. J. (1985): An automatic precipitation gauge based on vibrating-wire strain gauges. Nord. Hydrol., 16, 193-202, doi:10.2166/nh.1985.0015.

Bartelt, P. and Lehning, M. (2002): A physical SNOWPACK model for the Swiss avalanche warning. Part I:Numerical model. Cold Reg. Sci. Technol., 35, 123-145, doi:10.1016 S0165-232X(02)00074-5.

Bartelt, P., Salm, B. and Gruber, U. (1999): Calculating dense-snow avalanche runout using a Voellmy-fluid model with active/ passive longitudinal straining. J. Glaciol., 45, 242-254, doi:10.1017/s002214300000174x.

Battaglia, A., Rustemeier, E., Tokay, A., Blahak, U., Simmer, C. and County, B. (2010): PARSIVEL Snow Observations:A Critical Assessment. J. Atmos. Ocean. Technol., 27, 333-344, doi:10.1175/2009JTECHA1332.1

Bloemink, H. I. and Lanzinger, E. (2005): Precipitation type from the Thies disrometer. WMO Tech. Conf. on Meteorol. and Environ. Instruments and Methods of Observation (TECO2005), Bucharest, Romania, May 4-7, 2005, 3 (11).

Brawn, D. and Upton, G. (2008): Estimation of an atmospheric gamma drop size distribution using disdrometer data. Atmos. Res., 87, 66-79, doi:10.1016/j.atmosres.2007.07.006.

Call, D. A. (2005): Rethinking snowstorms as snow events:A regional case study from upstate New York. Bull. Am. Meteorol. Soc., 86, 1783-1793, doi:10.1175/BAMS-86-12-1783.

Call, D. A. (2010): Changes in ice storm impacts over time:18862000. Wea. Climate Soc., 2, 23-35, doi:10.1175/2009WCAS1013.1.

Cerruti, B. J. and Decker, S. G. (2012): A Statistical Forecast Model of Weather-Related Damage to a Major Electric Utility. J. Appl. Meteorol. Climatol., 51, 191-204, doi:10.1175/ JAMC-D-11-09.1.

Christen, M., Kowalski, J. and Bartelt, P. (2010): RAMMS: Numerical simulation of dense snow avalanches in threedimensional terrain. Cold Reg. Sci. Technol., 63, 1-14, doi:10.1016/j.coldregions.2010.04.005.

Coléou, C., Lesaffre, B., Brzoska, J.-B., Ludwig, W. and Boller, E. (2001): Three-dimensional snow images by X-ray microtomography. Ann. Glaciol., 32, 75-81, doi:10.3189/172756401781819418.

Colle, B. A., Stark, D. and Yuter, S. E. (2014): Surface microphysical observations within East Coast winter storms on Long Island, New York. Mon. Weather Rev., 142, 3126-3146, doi:10.1175/MWR-D-14-00035.1.

De Freitas, C. R. (1975): Estimation of the disruptive impact of snowfalls in urban areas. J. Appl. Meteorol., 14, 1166-1173, doi:10.1175/1520-0450 (1975) 014<1166:EOTDIO>2.0.CO; 2

Domine, F., Taillandier, A.-S., Cabanes, A., Douglas, T. A. and Sturm, M. (2009): Three examples where the specific surface area of snow increased over time. The Cryosphere, 3, 31-39, doi:10.5194/tc-3-31-2009.

Duchon, C. E. (2008): Using vibrating-wire technology for precipitation measurements. In Michaelides, S. (ed.),
Precipitation: Advances in measurement, estimation and prediction, Springer, Berlin, 33-58.

Goodison, B. E., Louie, P. Y. T. and Yang, D. (1998): WMO solid precipitation measurement intercomparison. WMO Instruments and Observing Methods Rep., 67, WMO/TD-872, $212 \mathrm{pp}$.

Hachikubo, A., Yamaguchi, S., Arakawa, H., Tanikawa, T., Hori, M., Sugiura, K., Matoba, S., Niwano, M., Kuchiki, K. and Aoki, T. (2014): Effects of temperature and grain type on time variation of snow specific surface area. Bull. Glaciol. Res. 32, 47-53. doi:10.5331/bgr.32.47.

Hachikubo, A., Yamaguchi, S., Shirawaka, T. and Aoki, T. (2017): Measurement of specific surface area of wet snow (in Japanese). Summaries of JSSI \& JSSE Joint Conf. on Snow and Ice Res., Sept. 24-27, 2017 Tokamachi, P245.

Hashimoto, A., Niwano, M., Aoki, T., Motoyoshi, H., Yamaguchi, S and Nakai, S. (2017): Transition of falling snow characteristics causing weak layer formation simulated by a numerical weather model, in avalanche disaster events on March 27, 2017 in Japan. Geophys. Res. Abst., 20, EGU201811121.

Hirashima, H., Abe, O., Sato, A. and Lehning, M. (2009): An adjustment for kinetic growth metamorphism to improve shear strength parameterization in the SNOWPACK model. Cold Reg. Sci. Technol., 59, 169-177, doi:10.1016/j. coldregions.2009.05.001

Hirashima, H., Abe, O. and Sato, A. (2011): Parameterization of the shear strength of faceted crystals during equitemperature metamorphism. Ann. Glaciol, 52 (58), 111-118, doi:10.3189/172756411797252310.

Hirashima, H., Yamaguchi, S. and Katsushima, T. (2014): A multidimensional water transport model to reproduce preferential flow in the snowpack. Cold Reg. Sci. Technol., 108, 80-90, doi:10.1016/j.coldregions.2014.09.004.

Hirashima, H., Avanzi, F. and Yamaguchi, S. (2017): Liquid water infiltration into a layered snowpack:evaluation of a 3-D water transport model with laboratory experiments. Hydrol. Earth Syst. Sci., 21, 5503-5515, doi:10.5194/hess-21-5503-2017.

Ishizaka, M. and Nohguchi, Y. (2012): Studies on capsizing of boats caused by 2010/2011 heavy snowfall at Tottori and Shimane Prefectures in Japan (in Japanese with English abstract and captions). Natural Disaster Res. Rept., 47, 9196.

Ishizaka, M., Shiina, T., Muramoto, K., Nakai, S. and Sato, A. (2004): An automated system foridentifying types of solid precipitation by image processing. Proc. 14th Int. Conf. on Clouds and Precipitation, July 19-23, 2004, Bologna, 11031106.

Ishizaka, M., Motoyoshi, H., Nakai, S., Shiina, T., Kumakura, T. and Muramoto, K. (2013): A new method for identifying the main type of solid hydrometeors contributing to snowfall from measured size-fall speed relationship. J. Meteorol. Soc. Jpn. Ser. II, 91, 747-762, doi:10.2151/jmsj.2013-602.

Ishizaka, M., Fujino, T., Motoyoshi, H., Nakai, S., Nakamura, K., Shiina, T. and Muramoto, K. (2015): Characteristics of snowfalls and snow crystals caused by two extratropical cyclones passing along the Pacific Ocean side of Japan on February 8 and 14-15 observed in Niigata district, 2014 -In relation to frequent occurrence of avalanches in KantoKoshin areas- (in Japanese with English abstract). J. Jpn. Soc. Snow and Ice (Seppyo), 77, 285-302.

Itado, A., Masuda, A., Taniguchi, K., Sakai, K., Uyeda, H., Kouketsu, T., Nakai, S., Ishizaka, M., Motoyoshi, H. and Yamashita, K. (2017): An approach for more precise winter precipitation estimation using XRAIN (in Japanese). The 2017 Spring Meeting of the Meteorol. Soc. Jpn., May 25-28, 2017, Tokyo, D452.

Ito, Y., Nishimura, K., Fujita, K., Yamaguchi, S., Izumi, K., Kawashima, K. and Kamiishi, I. (2016): Relationship between snow depth and extent of damage by snow avalanche in Langtang induced by the 2015 Gorkha Earthquake (in Japanese). Summaries of JSSI \& JSSE Joint Conf. 2016, 
Sept. 28-Oct. 2, 2016, Nagoya, B1-4.

Iwamoto, K., Yamaguchi, S., Nakai, S. and Sato, A. (2008): Forecasting experiments using the regional meteorological model and the numerical snow cover model in the snow disaster forecasting system. J. Natural Disaster Sci., 30, 3543, doi:10.2328/jnds.30.35.

Iwanami, K., Maki, M., Sato, T. and Higashiura, M. (1996): Distribution of precipitation parameters estimated from observations with a Doppler radar and a polarimetric radar: Part 2, Results from polarimetric radar observation. Proc. 12th Int. Conf. Clouds Precipitation, Jul. 29-Aug. 3, 2012, Zürich, 190-192.

Kamiishi, I. and Nakamura, K. (2018): "Cyclone-related avalanche" and its prediction system - to avoid tragic avalanche accidents (in Japanese). Mountaineering Educ., 33, 19-25.

Katsushima, T., Yamaguchi, S., Kumakura, T. and Sato, A. (2013): Experimental analysis of preferential flow in dry snowpack. Cold Reg. Sci. Technol., 85, 206-216, doi:10.1016/j. coldregions.2012.09.012

Kouketsu, T., Uyeda, H., Ohigashi, T., Oue, M., Takeuchi, H., Shinoda, T., Tsuboki, K., Kubo, M. and Muramoto, K. (2015): A hydrometeor classification method for X-Band polarimetric radar: Construction and validation focusing on solid hydrometeors under moist environments. J. Atmos. Ocean. Technol., 32, 2052-2074, doi:10.1175/JTECH-D-14-00124.1.

Kruger, A. and Krajewski, W. F. (2002): Two-dimensional video disdrometer:A description. J. Atmos. Ocean. Technol., 19, 602-617, doi:10.1175/1520-0426(2002)019<0602:tdvdad > 2.0. co;2.

Kumjian, M. R. and Lombardo, K. A. (2017): Insights into the Evolving Microphysical and Kinematic Structure of Northeastern U.S. Winter Storms from Dual-Polarization Doppler Radar. Mon. Weather Rev., 145, 1033-1061, doi:10.1175/ MWR-D-15-0451.1.

Lanzinger, E., Theel, M. and Windolph, H. (2006): Rainfall amount and intensity measured by the Thies laser precipitation monitor. TECO-2006-WMO Tech. Conf. Meteorol. Environ. Instruments and Methods of Observation, Geneva, Switzerland, Dec. 4-6, 2006, 3 (3).

Legagneux, L., Cabanes, A. and Dominé, F. (2002). Measurement of the specific surface area of 176 snow samples using methane adsorption at 77 K. J. Geophys. Res., 107 (D17), 4335, doi:10.1029/2001JD001016.

Lehning, M., Bartelt, P., Brown, B., Fierz, C. and Satyawali, P. (2002a): A physical SNOWPACK model for the Swiss avalanche warning. Part II:Snow microstructure. Cold Reg. Sci. Technol., 35, 147-167, doi:10.1016/S0165-232X(02)00072-1.

Lehning, M., Bartelt, P., Brown, B. and Fierz, C. (2002b): A physical SNOWPACK model for the Swiss avalanche warning. Part III:Meteorological forcing, thin layer formation and evaluation. Cold Reg. Sci. Technol., 35, 169-184, doi:10.1016/S0165-232X(02)00072-1.

Löffler-Mang, M. and Joss, J. (2000): An optical disdrometer for measuring size and velocity of hydrometeors. J. Atmos. Ocean. Technol., 17, 130-139, doi:10.1175/1520-0426 (2000) $017<0130$ :AODFMS>2.0.CO; 2.

Masuda, A., Itado, A., Taniguchi, K., Sakai, K., Uyeda, H., Yamashita, K. and Nakai, S. (2018): Improving of winter quantitative precipitation estimation using XRAIN. J. Jpn. Soc. Civ. Eng., Ser. B1, 74, I 85-I 90.

Matzl, M. and Schneebeli, M. (2006): Measuring specific surface area of snow by near infrared photography. J. Glaciol., 52 , 558-564, doi:10.3189/172756506781828412

Minda, H., Makino, T., Tsuda, N. and Kaneko, Y. (2016): Performance of a laser disdrometer with hydrometeor imaging capabilities and fall velocity estimates for snowfall. IEEJ Trans. on Electr. Electron. Eng., 11, 624-632, doi:10.1002/ tee.22280.

Misumi, R., Motoyoshi, H., Yamaguchi, S., Nakai, S., Ishizaka, M. and Fujiyoshi, Y. (2014): Empirical relationships for estimating liquid water fraction of melting snowflakes. $J$. Appl. Meteorol. Climatol., 53, 2232-2245, doi:10.1175/
JAMC-D-13-0169.1.

Motoyoshi, H. and Nakai, S. (2012): On heavy snowfall in the Aizu region of Fukushima Prefecture in December 2010 (in Japanese with English abstract and captions). Natural Disaster Res. Rept., 47, 17-31.

Motoyoshi, H., Ishizaka, M., Nakai, S. and Yamashita, K. (2016): On empirical parameterization of mass of hydrometeors using size and fall speed (in Japanese). Summaries of JSSI \& JSSE Joint Conf. 2016, Sept. 28-Oct. 2, 2016, Nagoya, P153.

Murakami, M., Yamada, Y., Matsuo, T. and Mizuno, H. (1992): Microphysical structures of warm-frontal clouds -The 20 June 1987 case study-. J. Meteorol. Soc. Japan, 70, 877-895, doi:10.2151/jmsj1965.70.5_877.

Muramoto, K. and Matsuura, K. (1993): A computer database for falling snowflakes. Ann. Glaciol., 18, 11-16, doi:10.1017/ s0260305500011186.

Muramoto, K., Shiina, T., Endo, T., Konishi, H. and Kitano, K. (1989): Measurement of snowflake size and falling velocity by image processing. Proc. NIPR Symp. Polar Meteorol. Glaciol., 2, 48-54.

Nakai, S. (2015): Variation and distribution of winter snow depth in Japan using "Seasonal Snow Depth Index" (in Japanese with English abstract). Bull. J. Meteorol. Soc. Jpn. (Tenki), 62, 187-199

Nakai, S. and Kumakura, T. (2007): Snowfall distribution characteristics of the heavy snow of the 2005/2006 Japanese winter:An analysis of the radar data of 3 months in 10-minute intervals (in Japanese with English abstract). J. Jpn. Soc. Snow and Ice (Seppyo), 69, 31-43, doi:10.5331/ seppyo.69.31.

Nakai, S. and Yamaguchi, S. (2012): Snowfall characteristics and the occurrence of related disasters during the heavy snowfall in 2010/2011 winter - Overview in whole Japan and the concentrated heavy snowfall in Tottori - (in Japanese with English abstract and captions). Natural Disaster Res. Rept., 47, 1-16.

Nakai, S., Sato, T., Sato, A., Hirashima, H., Nemoto, M., Motoyoshi, H., Iwamoto, K., Misumi, R., Kamiishi, I., Kobayashi, T. Kosugi, K., Yamaguchi, S., Abe, O. and Ishizaka, M. (2012): A Snow Disaster Forecasting System (SDFS) constructed from field observations and laboratory experiments. Cold Reg. Sci. Technol., 70, 53-61, doi:10.1016/j.coldregions.2011.09.002.

Nakai, S., Motoyoshi, H., Kumakura, T., Murakami, S. and Yokoyama, K. (2017): Radar estimation of solid precipitation intensity: A disdrometer-reference method and problems. Int. Workshop of falling snow and snow cover, Jan. 31-Feb. 1, 2017, Nagaoka.

Nakamura, K., Kamiishi, I. and Abe, O. (2014): Characteristic of avalanches caused by cyclonic heavy snowfall in February, 2014 (in Japanese). J. Snow Eng. Jpn., 30, 106-113.

Nakamura, K., Abe, O. and Kosugi, K. (2015): The establishment of an analytical method for three-dimensional X-ray microtomographic imaging with field snow and the application for the physical analysis of weak layers (in Japanese). Tohoku J. Snow Life, 30, 75-80.

Narita, H. (1969): Specific surface of deposited snow I (in Japanese with English summary). Low Temp. Sci., A27, 77-86.

Narita, H. (1971): Specific surface of deposited snow II (in Japanese with English summary). Low Temp. Sci., A29, 6981.

Nemoto, M., Kamiishi, I. and Nakamura, K. (2015): An application experiment of a blowing snow prediction system in Nakashibetsu, Hokkaido - 2014/15 winter - (in Japanese) Summaries of JSSI \& JSSE Joint Conf. 2015, Sept. 13-16, 2015 in Matsumoto, B1-2.

Nemoto, M., Nakamura, K. and Kamiishi, I. (2017): An experimental application of a blowing snow prediction system - Case studies in northern Nemuro, Hokkaido, 201617 winter - (in Japanese). Summaries of JSSI \& JSSE Joint Conf. 2017, Sept. 24-27, 2017, Tokamachi, P1-18.

NIED, (2016): Research report on wide area snow disasters 
associated with south-coast cyclones in February, 2014 and snow-related disasters in 2014/2015 winter (in Japanese with English abstract and captions). Natural Disaster Res. Rept., 49, $122 \mathrm{pp}$.

Nishimura, K. and Abe, O. (2011): Snow avalanche hazard map with Titan2D (in Japanese). Summaries of JSSI \& JSSE Joint Conf. 2011, Sept. 19-23, 2011, Nagaoka, P3-14.

Oda, K., Moriguchi, S., Kamiishi, I., Yashima, A., Sawada, K. and Sato, A. (2011): Simulation of a snow avalanche model test using computational fluid dynamics. Ann. Glaciol., 52 (58), 57-64, doi:10.3189/172756411797252284.

Oda, K., Takase, S., Moriguchi, S., Kamiishi, I., Uchiyama, S. Nakamura, K. and Abe, N. (2017): Reproduction of the NasuAvalanche which occurred on March 27 using threedimensional flow analysis (in Japanese). Summaries of JSSI \& JSSE Joint Conf. 2017, Sept. 24-27, 2017, Tokamachi A3-6.

Pitman, E. B., Nichita, C. C., Patra, A., Bauer, A., Sheridan, M. F. and Bursik, M. (2003): Computing granular avalanches and landslides. Phys. Fluids, 15, 3638-3646, doi:10.1063/1.1614253.

Pitman, E. B., Patra, A. K., Kumar, D., Nishimura, K. and Komori, J. (2013): Two phase Simulation of Glacier Lake Outburst Flows. J. Comput. Sci., 4, 71-79, doi:10.1016/j.jocs.2012.04.007.

Saito, K., Fujita, T., Yamada, Y., Ishida, J., Kumagai, Y., Aranami, K., Ohmori, S., Nagasawa, R., Kumagai, S., Muroi, C., Kato, T., Eito, H. and Yamazaki, Y. (2006): The operational JMA nonhydrostatic mesoscale model. Mon. Weather Rev., 134, 12661297, doi:10.1175/MWR3120.1.

Sanders, K.J. and Barjenbruch, B.L. (2016): Analysis of Ice-toLiquid Ratios during Freezing Rain and the Development of an Ice Accumulation Model. Wea. Forecast., 31, 1041-1060, doi:10.1175/WAF-D-15-0118.1.

Sato, A., (2004): Construction of snow disaster forecasting systemin Japan. In Bartelt, P., Adams, E., Christen, M., Sack, R. and Sato, A. (eds.), Snow Engineering V. A. A. Balkema Publishers, Leiden, 235-238.

Sato, K., Kosugi, K. and Mochizuki, S. (2012a): Air temperature dependency of snow accretion based on wind tunnle experiment data and characteristic conditions of wet snowfall in Tohoku District (in Japanese). Tohoku J. Snow Life, 27, 56-58.

Sato, K., Mochizuki, S. and Abe, O. (2012b): Mechanical-draft method to control water content of the artificial snow for snow accretion experiments (in Japanese). Summaries of JSSI \& JSSE Joint Conf. 2011, Sept. 19-23, 2011, Nagaoka, $\mathrm{P} 3-38$

Sato, K., Kosugi, K. and Mochizuki, S. (2013): Wind tunnel experiments on snowflake type dependency of snow accretion (in Japanese). Summaries of JSSI \& JSSE Joint Conf. 2013, Sept. 17-21, 2013 in Kitami, P2-29.

Sato, T. (2012): Snow and ice damage to human and buildings in the Tohoku District during 2010/2011 winter (in Japanese with English abstract and captions). Natural Disaster Res. Rept., 47, 63-70.

Sato, T., Kosugi, K. and Sato, A. (2004): Development of saltation layer of drifting snow. Ann. Glaciol., 38, 35-38, doi:10.3189/ 172756404781815211.

Sato, T. Nemoto, M., Kamiisi, I., Motoyoshi, H. and Nakai, S. (2012c): Prediction of poor visibility due to blowing snow and its verification - Application to measures against blowing snow disasters by Niigata City during 2010/2011 winter - (in Japanese with English abstract and captions). Natural
Disaster Res. Rept., 47, 103-112.

Schönhuber, M., Lammer, G. and Randeu, W. L. (2007): One decade of imaging precipitation measurement by 2D-videodisdrometer. Adv. Geosci., 10, 85-90, doi:10.5194/ adgeo-10-85-2007.

Shiina, T., Ishizaka, M., Muramoto, K., Nakai, S., Sato, A. and Iwamoto, K. (2004): A method forautomated identifica- tion of types of solid precipitation by image processing: Part $1 \mathrm{~A}$ measurement method of diameter and fall speed by image processing (in Japanese with English abstract). J. Jpn. Soc. Snow and Ice (Seppyo) , 66, 637-646.

Solheim, F. S., Godwin, J. R., Westwater, E. R., Han, Y., Keihm, S. J., Marsh, K. and Ware, R. (1998): Radiometric profiling of temperature, water vapor, and cloud liquid water using various inversion methods. Radio Sci., 33, 393-404, doi:10. 1029/97RS03656.

Tamura, M, (1993): An automatic system for controlling snow on roofs. Ann. Glaciol, 18, 113-116, doi:10.1017/s0260305500011356.

Wakahama, G. (1979): Experimental studies of snow accretion on electric lines developed in a strong wind. J. Natural Disaster Sci., 1, 21-33.

Wakahama, G., Kuroiwa, D. and Goto, K. (1977): Snow accretion on electric wires and its prevention. J. Glaciol., 19, 479-487.

Ware, R., Carpenter, R., Guldner, J., Liljegren, J., Nehrkorn, T., Solheim, F. and Vandenberghe, F. (2003): A multichannel radiometric profiler of temperature, humidity and cloud liquid, Radio Sci., 38 (4), 8079, doi:10.1029/2002RS002856.

Yamaguchi, S., Abe, O., Nakai, S. and Sato, A. (2007): Recent snow cover fluctuations in the mountainous areas of Japan. Glacier mass balance changes and meltwater discharge (Symp. at Foz do Iguaçu, Brazil - Glacier Mass Balance Changes and Meltwater Discharge). IAHS Publ. (318), 116125.

Yamaguchi, S., Abe, O., Nakai, S. and Sato, A. (2011): Recent fluctuations of meteorological and snow conditions in Japanese mountains. Ann. Glaciol., 52, 209-215, doi:10. 3189/172756411797252266

Yamaguchi, S., Motoyoshi, H., Tanikawa, T., Aoki, T., Niwano, M., Takeuchi, Y. and Endo, Y. (2014): Application of snow specific surface area measurement using an optical method based on near-infrared reflectance around 900-nm wavelength to wet snow zones in Japan. Bull. Glaciol. Res. 32, 55-64. doi:10.5331/bgr.32.55.

Yamaguchi, S., Ishizaka, M., Motoyoshi, H., Hachikubo, A., Aoki, T., Hashimoto, A., Nakai, S. and Yamashita, K. (2016): Investigation of specific surface area of new snow (in Japanese). Summaries of JSSI \& JSSE Joint Conf. 2016, Sept. 28-Oct. 2, 2016, Nagoya, B3-12.

Yamaguchi, S., Ishizaka, M., Motoyoshi, H., Yamashita, K., Nakai, S., Hashimoto, A., Vionnet, V., Hachikubo, A. and Aoki, T. (2017a): Investigation of specific surface area of new snow (2) (in Japanese). Summaries of JSSI \& JSSE Joint Conf. 2017, Sept. 24-27, 2017, Tokamachi, B1-9.

Yamaguchi, Y., Takase, S., Moriguchi, S., Terada, K., Oda, K. and Kamiishi, I. (2017b): Three-dimensional nonstructural finite element analysis of snow avalanche using non-Newtonian fluid model. Trans. JSCES, Paper No.20170011, doi:10.11421/ jsces.2017.20170011.

Yamashita, K., Nakai, S., Motoyoshi, H. and Ishizaka, M. (2019): An observation system for monitoring of local severe snowstorm causing snow-related disaster. Bull. Glaciol. Res., 37S, 21-30, doi:10.5331/bgr.18SR01. 